Article

\title{
Feasibility Study of a Scroll Expander for Recycling Low-Pressure Exhaust Gas Energy from a Vehicle Gasoline Engine System
}

\author{
Xing Luo ${ }^{1}$, Jihong Wang ${ }^{1,2, *}$, Christopher Krupke ${ }^{1}$ and Hongming $\mathrm{Xu}^{3}$ \\ 1 School of Engineering, University of Warwick, Coventry CV4 7AL, West Midlands, UK; \\ xing.luo@warwick.ac.uk (X.L.); c.krupke@warwick.ac.uk (C.K.) \\ 2 School of Electrical \& Electronic Engineering, Huazhong University of Science \& Technology, \\ Wuhan 430074, China \\ 3 School of Mechanical Engineering, University of Birmingham, Birmingham B15 2TT, UK; \\ h.m.xu@bham.ac.uk \\ * Correspondence: jihong.wang@warwick.ac.uk or jihongwang@hust.edu.cn; Tel.: +44-024-765-23780; \\ Fax: +44-024-764-18922
}

Academic Editor: Chang Sik Lee

Received: 11 January 2016; Accepted: 17 March 2016; Published: 24 March 2016

\begin{abstract}
The growing number of vehicles on the road has led to a rapid increase in fuel consumption and toxic gas emissions, so the challenges in fuel efficiency improvement and reduction of $\mathrm{CO}_{2}$ and $\mathrm{NO}_{x}$ emissions have always been on the top agenda of the automotive industry. The paper presents a feasibility study of recovering the low-pressure exhaust gas energy via by-pass connection of a scroll expander to the engine system exhaust. The paper starts with the description of the proposed new exhaust energy recycling scheme and the mathematical modelling of the system. A feasibility study is carried out to investigate whether this new scheme can work with the engine operation conditions specified by the engine test data. The initial study indicated that the scroll expander structure needs to be modified; otherwise, it cannot be used for exhaust energy recovery. The experimental test and simulation results presented in this paper indicate that it is feasible to recover the low-pressure exhaust gas energy using a scroll expander with a modified structure. The proposed energy recovery system has the potential to produce over $400 \mathrm{~W}$ power output with over $90 \%$ of engine exhaust flow recycling.
\end{abstract}

Keywords: scroll expander; gasoline engine; exhaust energy recovery

\section{Introduction}

With economic and technical developments, the number of road vehicles is rapidly increasing worldwide. In Great Britain, there were 35.6 million licensed vehicles on the road at the end of December 2014; and the UK was the second largest new car market in Europe in 2014, accounting for $20 \%$ of all new cars registered in the EU that year [1]. In China, according to a statement by the Chinese Ministry of Public Security, the vehicle population reached 264 million at the end of 2014, with an average annual increase of 15 million vehicles from 2010 to 2014 [2]. Also in the United States, the number of registered cars and light trucks reached 252.6 million in 2014, with an increase of about 3.9 million from the number of registered vehicles in 2012 [3]. Currently, most vehicles are driven by internal combustion engines, which implies a huge consumption of the limited fossil fuels. Meanwhile, harmful exhaust gases (especially $\mathrm{CO}_{2}$ and $\mathrm{NO}_{x}$ emissions) are heavily produced during the operation of these vehicles. Therefore, energy savings from the engine system is one of the core strategies to both economize on fossil fuels and achieve $\mathrm{CO}_{2}$ and $\mathrm{NO}_{x}$ emission reductions. 
In regard to the energy conversion of the engine working process, there is extensive room for improvement. According to a statement about fuel economy from the Department of Energy of the U.S. Government, only about $14 \%-30 \%$ of the energy from the fuel is used in an internal combustion engine-powered vehicle to provide the driving force $[4,5]$. The rest of the energy is lost due to low engine and driveline efficiencies and heat losses. To save the limited fuels and meet emission standard targets ([6]), improving the energy conversion ability of vehicle systems whilst reducing toxic gas emissions represents a significant challenge.

Both industrial and academic sectors are making great efforts to develop effective methods to reduce vehicle energy consumption, such as developing an efficient Homogeneous Charge Compression Ignition (HCCI) engine, investigating predictive control algorithms for engine cooling systems and assessing supercharging boosting components for heavily downsized gasoline engines [7-9]. Reusing the exhaust gas energy from an engine discharge path can also be considered as a good option. There are several approaches to utilize the exhaust energy to improve the vehicle energy efficiency and to make it run with reduced emissions. For instance, the heat from the exhaust can be used to warm the engine components, and the interior of the vehicle can be warmed using the exhaust heat as well [10]. Design and optimization of heat exchangers, and the use of organic fluids and ammonia as working media for vehicle waste heat recovery applications have been studied [11-13]. Furthermore, implementing an Exhaust Gas Recirculation (EGR) into a vehicle engine system is nowadays a popular technology, which can achieve reduced $\mathrm{NO}_{x}$ emissions and potentially improve the trade-off relationship between the emissions and fuel consumption $[14,15]$. For example, studies on EGR and its effect on the trade-off relationship in natural gas spark-ignition (SI) engines can be found in $[16,17]$. It should be noted that the vehicle exhaust can also be used to generate electricity. For implementing such an application, a device with high energy conversion ability and good stability while working at low pressures will be required, because the engine exhaust is normally at a low pressure.

The scroll expander (also named the scroll air motor) offers the possibility of reusing the vehicle exhaust flow to generate electricity, which leads to the research described herein-a feasibility study of the recycling the engine exhaust gas energy via the scroll expander technology. The scroll expander's unique structure inherited from the scroll compressor brings its key advantage-relatively high energy efficiency (up to around $70 \%$ and potentially even higher) under the proper working conditions compared to some other pneumatic actuators, such as pneumatic cylinders and vane-type air motors [18-22]. This technology has recently been successfully adopted in some smart energy conversion systems. For instance, the company Flowbattery Ltd. (Chester, UK) produces a unique product-Compressed Air Batteries (CAB). The CAB is a type of hybrid Uninterrupted Power Supply (UPS) which uses a set of compressed air devices integrated with an ultra-capacitor bank to provide back-up power; the $\mathrm{CAB}$ has been implemented in UK grid and data centers to replace conventional battery powered UPS systems [21]. The company is also developing Micro Combined Heat \& Power systems (Micro CHP) which can generate heat and electricity simultaneously on a $\mathrm{kW}$-scale to provide energy for a residence or a small commercial building. In both the CAB and Micro CHP designs, a scroll expander is used to drive the electrical generator for achieving efficient energy conversion. Furthermore, academia has widely investigated the feasibility of recovering the exhaust energy using scroll technology in different applications, such as a combination scroll compressor-expander mechanism for recycling work in a fuel cell system ([22]), an exhaust compressed air recycling system for recovering energy from conventional pneumatic actuating systems ([23]), and a waste heat-to-power research project—using scroll expanders for an Organic Rankine Bottoming Cycle ([24]). 


\section{Mathematical Modelling of the Engine Exhaust Recycling System}

\subsection{Description of the Proposed Engine Exhaust Recycling System}

The paper presents a new scheme for vehicle gasoline engine exhaust energy recovery via connecting a scroll expander at the engine system discharge port. A schematic diagram of the proposed design is illustrated in Figure 1. It shows the structure of a conventional vehicle internal combustion engine system and the exhaust recycling system, including their connection. From Figure 1, the working medium goes through low and high pressure (LP and HP) compressors to obtain an average value of around $1.7 \times 10^{5}$ Pa before entering the cylinders. After the combustion process happens in the cylinders, the exhaust goes through HP and LP turbines and discharges from the outlet of the engine system. Then, via the designed exhaust energy recovery system a part of exhaust flows into the down-stream scroll expander through a controlled valve and a filter. The scroll expander converts the exhaust energy into crank kinetic energy which is finally transformed into electrical energy by a generator equipped with a gear transmission.

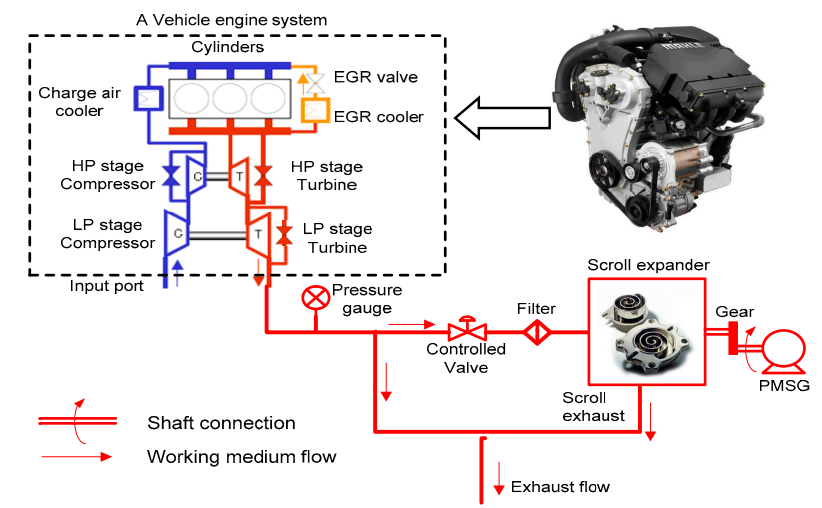

Figure 1. Schematic diagram of connecting a vehicle engine system with an exhaust energy recovery system (picture courtesy of MAHLE).

The paper starts with the mathematical modelling of the dynamic process of the proposed recycling scheme as shown in Figure 1. The measured operation data (pressure, flow rate and temperature) from a gasoline engine discharge port is used to compare and examine the working conditions of the scroll expander for the exhaust energy recovery application. The investigation of recovering exhaust gas energy is carried out, in which an original scroll expander is used for initial experimental and simulation studies to identify its limitations. Then the various designs of the scroll expander structure are proposed and examined via extensive simulation study.

\subsection{Mathematical Modelling of the Engine Exhaust Recycling System}

The scroll expander is the most important component of the proposed exhaust recycling system. Its compact mechanical structure leads to its high efficiency (up to around $70 \%$ and potentially even higher) [18-22]. Figure 2 shows the structure of an unmodified scroll expander, which inherits is configuration from a from Sanden TRS09 scroll compressor. The scroll expander consists of two intermeshed identical spirals, namely the fixed scroll and the moving scroll, respectively. The two scrolls form a center chamber and an even number of sealed side crescent chambers. The inlet and the outlet are individually located at the center chamber and the exhaust chamber of the scroll expander. The compressed gas expands through three phases: charging, expansion and discharging. In this process, the compressed gas pushes the expander center and side chambers getting bigger in each cycle; the expanding crescent sealed side chambers immediately open at some moment in each cycle and they do not exist anymore during the rest of each cycle; the moving scroll does not rotate but 
rather wobbles on a cam which connects to the expander shaft; the overall generalized motion from the moving scroll movement is the rotation of the shaft (for details, refer to $[25,26]$ ).

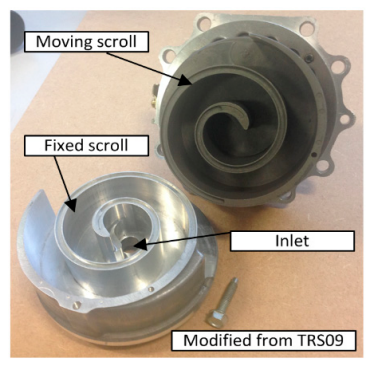

(a)

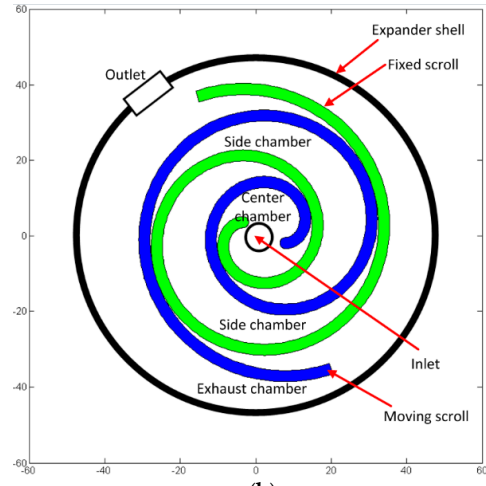

(b)

Figure 2. Illustration of the unmodified scroll expander structure (Sanden scroll TRS09): (a) moving and fixed scrolls with their base plates; and (b) schematic diagram of the expander chambers.

To simplify the analysis, the following assumptions are made: the gas used for driving the scroll expander is an ideal gas and the gas is uniformly distributed in each chamber; during the scroll expander operation, the leakage effect inside the scroll expander is neglected. The first law of thermodynamics, the steady-flow theory, the energy and mass balances, the ideal gas law with other relevant thermodynamic fundamentals are used to drive the equations of the gas temperatures and pressures inside the expander chambers. The detailed modelling process for scroll expanders with using compressed air as working medium can be found in $[20,25,27]$, which is briefly described below. For the center chamber of scroll expanders:

$$
\begin{gathered}
V_{\mathrm{sc}}\left(\alpha_{\mathrm{s}}\right)=z\left[\left(x_{0} k \pi-k^{2} \pi-x_{0} r_{\mathrm{s}}+r_{\mathrm{s}} k\right) \cos \alpha_{\mathrm{s}}+k^{2} \pi \alpha_{\mathrm{s}}^{2}+\left(r_{\mathrm{s}} \rho_{0} k \pi-r_{\mathrm{s}} \rho_{0}-y_{0} r_{\mathrm{s}}+y_{0} k \pi\right) \sin \alpha_{\mathrm{s}}\right. \\
\left.-r_{\mathrm{s}} k+\frac{1}{3} k^{2} \pi^{3}+\left(r_{\mathrm{s}} \pi k+2 k \rho_{0} \pi\right) \alpha_{\mathrm{s}}-\frac{1}{2} r_{\mathrm{s}} \pi^{2} k+\rho_{0} r_{\mathrm{s}} \pi+\frac{1}{2} r_{\mathrm{s}}^{2} \pi+\rho_{0}^{2} \pi\right] \\
\dot{T}_{\mathrm{sc}}=\frac{\frac{\dot{m}_{\mathrm{in}} h_{\mathrm{in}}}{V_{\mathrm{sc}}}-\frac{\dot{V}_{\mathrm{sc}}}{V_{\mathrm{sc}}}\left[X_{\mathrm{air}}\right] \bar{h}_{\mathrm{sc}}-\left[\dot{X}_{\mathrm{air}}\right] \bar{h}_{\mathrm{sc}}+P_{\mathrm{sc}}\left[\dot{X}_{\mathrm{air}}\right] /\left[X_{\mathrm{air}}\right]}{\left[X_{\mathrm{air}}\right] C_{\mathrm{p}, \mathrm{air}}\left(T_{\mathrm{sc}}\right)-P_{\mathrm{sc}} / T_{\mathrm{sc}}} \\
\dot{P}_{\mathrm{sc}}=\frac{1}{V_{\mathrm{sc}}}\left(\frac{\dot{m}_{\mathrm{sc}}}{M_{\mathrm{air}}} R T_{\mathrm{sc}}+R \dot{T}_{\mathrm{sc}} \frac{m_{\mathrm{sc}}}{M_{\mathrm{air}}}-P_{\mathrm{sc}} \dot{V}_{\mathrm{sc}}\right)
\end{gathered}
$$

For the side chamber of scroll expanders:

$$
\begin{gathered}
V_{\mathrm{ss}}\left(\alpha_{\mathrm{s}}, n_{\mathrm{s}}\right)=z\left[\pi r_{\mathrm{s}}^{2}+2 \pi r_{\mathrm{s}}\left(\rho_{0}+k\left(\alpha_{\mathrm{s}}+\pi+2\left(n_{\mathrm{s}}-1\right) \pi\right)\right)\right] \\
\dot{T}_{\mathrm{ss}}=\frac{-\left(\dot{V}_{\mathrm{ss}} / V_{\mathrm{ss}}\right)\left(\left[X_{\mathrm{air}}\right] \bar{h}_{\mathrm{ss}}\right)-\left[\dot{X}_{\mathrm{air}}\right] \bar{h}_{\mathrm{ss}}+P_{\mathrm{ss}}\left[\dot{X}_{\mathrm{air}}\right] /\left[X_{\mathrm{air}}\right]}{\left[X_{\mathrm{air}}\right] C_{\mathrm{p}, \mathrm{air}}\left(T_{\mathrm{ss}}\right)-P_{\mathrm{ss}} / T_{\mathrm{ss}}} \\
\dot{P}_{\mathrm{ss}}=\frac{1}{V_{\mathrm{ss}}}\left(R \dot{T}_{\mathrm{ss}} \frac{m_{\mathrm{ss}}}{M_{\mathrm{air}}}-P_{\mathrm{ss}} \dot{V}_{\mathrm{ss}}\right)
\end{gathered}
$$

For the exhaust chamber of scroll expanders:

$$
\begin{gathered}
V_{\mathrm{se}}\left(\alpha_{\mathrm{s}}\right)=V_{\mathrm{tol}}-V_{\mathrm{sc}}\left(\alpha_{\mathrm{s}}\right)-\sum V_{\mathrm{ss}}\left(\alpha_{\mathrm{s}}, n_{\mathrm{s}}\right) \\
\dot{T}_{\mathrm{se}}=\frac{-\frac{\dot{m}_{\mathrm{out}} h_{\mathrm{se}}}{V_{\mathrm{se}}}-\frac{\dot{V}_{\mathrm{se}}}{V_{\mathrm{se}}}\left(\left[X_{\mathrm{air}}\right] \bar{h}_{\mathrm{se}}\right)-\left[\dot{X}_{\mathrm{air}}\right] \bar{h}_{\mathrm{se}}+P_{\mathrm{se}} \frac{\left[\dot{X}_{\mathrm{air}}\right]}{\left[X_{\mathrm{air}}\right]}}{\left[X_{\mathrm{air}}\right] C_{\mathrm{p}, \text { air }}\left(T_{\mathrm{se}}\right)-P_{\mathrm{se}} / T_{\mathrm{se}}}
\end{gathered}
$$




$$
\dot{P}_{\mathrm{se}}=\frac{1}{V_{\mathrm{se}}}\left(\frac{\dot{m}_{\mathrm{se}}}{M_{\mathrm{air}}} R T_{\mathrm{se}}+R \dot{T}_{\mathrm{se}} \frac{m_{\mathrm{se}}}{M_{\mathrm{air}}}-P_{\mathrm{se}} \dot{V}_{\mathrm{se}}\right)
$$

For the generated torque of scroll expanders:

$$
\tau_{\mathrm{scroll}}=-K_{S-C 1} S\left(\omega_{\mathrm{s}}\right)-K_{\mathrm{fs}} \omega_{\mathrm{s}}+\sum_{n_{\mathrm{s}}=0,1,2, \ldots} z r_{\mathrm{s}} \hat{P}\left(2 \rho_{0}+2 \gamma \alpha_{\mathrm{s}}+\left(4 n_{\mathrm{s}}+1\right) \gamma \pi\right)
$$

where the subscripts $s c$, ss and se stand for the scroll expander center, side and exhaust chambers, respectively; the subscripts in, out represent the inlet and the outlet ports respectively; $m$ is the mass of air; $\dot{m}$ is the air mass flow rate; $V$ represents volume in general; $V_{\text {tol }}$ is the total control volume inside the scroll expander shell; $P$ is air pressure; $T$ is the air temperature; the initial point of the moving scroll is defined at the position $\left(x_{0}, y_{0}\right) ; n_{\mathrm{s}}$ is the number of scroll wraps; $\rho_{0}$ is the initial radius of the curvature of the moving scroll curve; $\left[X_{\text {air }}\right]$ represents the molar volumetric concentration of air; $R$ is the ideal gas constant; $M_{\text {air }}$ is the molar mass of air; $\bar{h}$ is the specific enthalpy of the air on a molar basis; $C_{\mathrm{p}, \text { air }}(T)$ refers to the specific heat of air at the temperature $T ; h$ stands for the air enthalpy; $\omega_{\mathrm{s}}$ is the scroll expander rotor angular speed; $\tau_{\text {scroll }}$ is the shaft torque of the scroll expander; $k$ refers to the slope of the curvature radius; $\hat{P}$ is pressure difference between the adjacent chambers of the scroll expander; $r_{\mathrm{s}}$ is the radius of the orbit relevant to the moving scroll motion (for details, refer to [20]); $\alpha_{\mathrm{s}}$ stands for the current orbit angle of the moving scroll; $z$ is the height of the two scrolls; $K_{\mathrm{fs}}$ is defined as the coefficient of the scroll viscous friction; $K_{S-C} S\left(\omega_{\mathrm{S}}\right)$ stands for the combination effect on torque from the static and Coulomb frictions, and the detailed explanation of the scroll expander frictions was described in $[20,23,27] ; \dot{m}_{\mathrm{in}}, \dot{m}_{\text {out }}$ are the inlet and outlet mass flow rates which can be calculated by the orifice theory $([7,20])$ :

$$
\dot{m}_{\text {ori }}=C_{\mathrm{d}} C_{0} A_{\text {ori }} P_{\mathrm{u}} f\left(\frac{P_{\mathrm{d}}}{P_{\mathrm{u}}}\right) / \sqrt{T_{\mathrm{u}}}
$$

where: $f\left(\frac{P_{\mathrm{d}}}{P_{\mathrm{u}}}\right)=\left\{\begin{array}{cc}1 & \text { for choked flow }\left(\frac{P_{\mathrm{d}}}{P_{\mathrm{u}}} \leqslant c_{\mathrm{r}}\right) \\ C_{\mathrm{k}}\left(\left(\frac{P_{\mathrm{d}}}{P_{\mathrm{u}}}\right)^{2 / \gamma}-\left(\frac{P_{\mathrm{d}}}{P_{\mathrm{u}}}\right)^{(\gamma+1) / \gamma}\right)^{1 / 2} & \text { for unchoked flow }\left(\frac{P_{\mathrm{d}}}{P_{\mathrm{u}}}>c_{\mathrm{r}}\right)\end{array}\right.$

$A_{\text {ori }}$ is the effective open area of the orifice; $C_{\mathrm{d}}$ is the discharge coefficient whose range is normally from 0.6 to $1.0 ; C_{\mathrm{k}}=\left[\frac{2}{\gamma-1}\left(\frac{\gamma+1}{2}\right)^{\frac{\gamma+1}{\gamma-1}}\right]^{\frac{1}{2}} ; c_{\mathrm{r}}=\left(\frac{P_{\mathrm{d}}}{P_{\mathrm{u}}}\right)_{c_{\mathrm{r}}}=\left(\frac{2}{\gamma+1}\right)^{\frac{\gamma}{\gamma-1}}$; $C_{0}=\left[\frac{\gamma M_{\text {air }}}{R}\left(\frac{2}{\gamma+1}\right)^{\frac{\gamma+1}{\gamma-1}}\right]^{\frac{1}{2}} ;$ for air, $\gamma=1.4, c_{\mathrm{r}}=0.528, C_{\mathrm{k}}=3.864, C_{0}=0.0404 ; \gamma$ is the ratio of specific heats.

The developed scroll expander mathematical model was validated by the authors' laboratory and the relevant details can be found in [20].

\subsection{Mathematical Modelling for Permanent Magnet Synchronous Generators}

A permanent magnet synchronous generator (PMSG) is connected to the scroll expander shaft and is driven by the expander for electricity generation as the exhaust energy recovery output. The PMSG is chosen mainly because its high efficiency compared with asynchronous generators. In developing the dynamic model of the PMSG, Park's transformation is used for simplifying the analysis of three-phase circuits $([28,29])$. It is a transformation of coordinates from the three-phase stationary coordinate system $\left(R_{\mathrm{g}}\right)$ to the direct-quadrature-zero rotating coordinate system $\left(\overrightarrow{\mathbf{X}}_{\mathrm{dq} 0}\right)$. To the PMSG load circuit, the same resistances between each of the two phases are used, and thus it is assumed that it is a 
complete balanced three-phase load circuit. In this case, the application of the dq0 system reduces the three AC quantities $\left(\overrightarrow{\mathbf{X}}_{\mathrm{dq} 0}\right)$ to the two DC quantities $\left(p_{\mathrm{g}}\right)$. It is often used in order to simplify the analysis of three-phase synchronous machines. From the $q$ axis and the $d$ axis equivalent circuits of the PMSG (for details, refer to $[28,29]$ ) and also Newton's Law for rotary motion, a mathematical model for the PMSG systems can be described by $([28,29])$ :

$$
\begin{gathered}
\dot{\omega}_{\mathrm{g}}=\frac{1}{J_{\text {total }}}\left[\xi \tau_{\text {scroll }}-\tau_{\mathrm{e}}-K_{S-C 2} S\left(\omega_{\mathrm{g}}\right)-\left(K_{\text {fgear }}+K_{\text {fgen }}\right) \omega_{\mathrm{g}}\right] \\
\dot{\theta}_{\mathrm{g}}=\omega_{\mathrm{g}} \\
\dot{i}_{\mathrm{d}}=\frac{1}{L_{\mathrm{d}}} v_{\mathrm{d}}-\frac{R_{\mathrm{g}}}{L_{\mathrm{d}}} i_{\mathrm{d}}+\frac{L_{\mathrm{q}}}{L_{\mathrm{d}}} p_{\mathrm{g}} \omega_{\mathrm{g}} i_{\mathrm{q}} \\
\dot{i}_{\mathrm{q}}=\frac{1}{L_{\mathrm{q}}} v_{\mathrm{q}}-\frac{R_{\mathrm{g}}}{L_{\mathrm{q}}} i_{\mathrm{q}}-\frac{L_{\mathrm{d}}}{L_{\mathrm{q}}} p_{\mathrm{g}} \omega_{\mathrm{g}} i_{\mathrm{d}}-\frac{\lambda p_{\mathrm{g}} \omega_{\mathrm{g}}}{L_{\mathrm{q}}} \\
\tau_{\mathrm{e}}=\frac{3}{2} p_{\mathrm{g}}\left[\lambda i_{\mathrm{q}}+\left(L_{\mathrm{d}}-L_{\mathrm{q}}\right) i_{\mathrm{d}} i_{\mathrm{q}}\right] \\
v_{\mathrm{q}}=\frac{1}{3}\left[\cos \left(p_{\mathrm{g}} \theta_{\mathrm{g}}\right) \times\left(2 v_{\mathrm{ab}}+v_{\mathrm{bc}}\right)+\sqrt{3} v_{\mathrm{bc}} \sin \left(p_{\mathrm{g}} \theta_{\mathrm{g}}\right)\right] \\
v_{\mathrm{d}}=\frac{1}{3}\left[\sin \left(p_{\mathrm{G}} \theta_{\mathrm{G}}\right) \times\left(2 v_{\mathrm{ab}}+v_{\mathrm{bc}}\right)+\left(-\sqrt{3} v_{\mathrm{bc}} \cos \left(p_{\mathrm{G}} \theta_{\mathrm{G}}\right)\right)\right]
\end{gathered}
$$

where the subscripts $a, b, c, d, q$ represent the $a, b, c, d, q$ axes, respectively; $\omega_{\mathrm{g}}$ refers to the PMSG rotor speed; $K_{S-C 2} S\left(\omega_{\mathrm{g}}\right)$ stands for the combination of effect on torque from the static and Coulomb frictions of the PMSG and the gear; $K_{f g e n}$ and $K_{f g e a r}$ are the coefficients of the viscous frictions to the PMSG and the gear; $\xi$ is the gear transmission ratio; $J_{\text {total }}$ represents the inertia of the whole energy recycling system; $\tau_{\mathbf{e}}$ is the PMSG electromagnetic torque; $\theta_{\mathrm{g}}$ is the PMSG rotor angular position; $L_{\mathrm{q}}, L_{\mathrm{d}}$ stand for the resulting $q$ and $d$ axis inductances, respectively; $R_{\mathrm{g}}$ is the resistance of the stator windings; $p_{\mathrm{g}}$ is the number of pole pairs of the PMSG; $\lambda$ is the amplitude of flux; $i$ and $v$ refer to the current and voltage in the different axes. To the designed system, a pure resistance circuit is connected to the PMSG electrical output with a balanced star connection. Thus, Park's transformation can be described as ([28,29]):

$$
\mathbf{X}_{\mathrm{dq}}=\mathbf{T}_{\mathrm{park}} \boldsymbol{X}_{\mathrm{abc}}
$$

where $\mathbf{X}_{\mathrm{abc}}=\left[\begin{array}{lll}i_{\mathrm{a}} & i_{\mathrm{b}} & i_{\mathrm{c}}\end{array}\right]^{\mathrm{T}}, \mathbf{X}_{\mathrm{dq}}=\left[\begin{array}{ll}i_{\mathrm{d}} & i_{\mathrm{q}}\end{array}\right]^{\mathrm{T}}$, and

$$
\mathbf{T}_{\text {park }}=\frac{2}{3}\left[\begin{array}{ccc}
\cos \omega_{\mathrm{g}} t & \cos \left(\omega_{\mathrm{g}} t-\frac{2}{3} \pi\right) & \cos \left(\omega_{\mathrm{g}} t+\frac{2}{3} \pi\right) \\
-\sin \omega_{\mathrm{g}} t & -\sin \left(\omega_{\mathrm{g}} t-\frac{2}{3} \pi\right) & -\sin \left(\omega_{\mathrm{g}} t+\frac{2}{3} \pi\right)
\end{array}\right]
$$

The whole exhaust recycling system model can be finally developed by integrating the mathematical models for scroll expanders and PMSGs with electrical loads. The modelling equations described in Sections 2.2 and 2.3 are implemented in the Matlab/Simulink software environment to solve the equations simultaneously. In numerical analysis, the Dormand-Prince method is chosen for solving the differential equations.

\section{Results and Discussion}

\subsection{Recovering Exhaust Energy Using an Unmodified Scroll Expander}

Through the initial experimental test analysis and the simulation study using the developed exhaust recycling system model, this section focuses on the feasibility study of exhaust energy recycling 
via an unmodified scroll expander which is available in the laboratory. For this analysis, the following assumptions are made:

(1) After a post-combustion gas filter (or other similar function devices) operation, the exhaust gas from the engine system can flow into the scroll expander without any possible damage to the scroll mechanism (Figure 1)

(2) The effect of gas leakage between scroll chambers is not taken into consideration;

(3) In practice, after the exhaust energy recycling system connecting to the discharge port, the original engine system working conditions may be affected because the down-stream gas pressure of the scroll expander could possibly propagate back to the up-stream. In our analysis, this is not considered at the moment. The engine system exhaust is treated as a "stable gas supply with low pressure $\left(1.30 \times 10^{5} \mathrm{~Pa}\right)$ and high temperature $(947.50 \mathrm{~K})$ " to the scroll expander.

(4) It is assumed that the sufficient combustion process happens in the gasoline engine cylinders and all the reactants convert to the products via the combustion. Then the corresponding chemical reaction can be described as $([30,31]): 2 \mathrm{C}_{8} \mathrm{H}_{18}+25 \mathrm{O}_{2} \rightarrow 16 \mathrm{CO}_{2}+18 \mathrm{H}_{2} \mathrm{O}$. Therefore, the properties of the post-combustion mixture will be considered and used in the relevant simulation study.

According to the chemical reaction happened in the combustion process of gasoline engines, the average molar mass of the post-combustion mixture can be calculated. The ratio of specific heats of the mixture in the gasoline engine cylinders varies from 1.25 to 1.38 (refer to [32]) and thus the average ratio of specific heats of the mixture $(\gamma=1.315)$ is used in this paper. Some parameters (such as $C_{k}$, $C_{0}, c_{\mathrm{r}}$ ) to the scroll expander mathematical model need to be re-calculated (Equation (11)), and the mathematical descriptions of the temperature and pressure variations in the different scroll expander chambers need to be re-considered:

$$
\begin{aligned}
& \dot{T}_{\text {ch_mix }}=\frac{\frac{\sum \dot{m}_{\mathrm{in}, i} h_{\mathrm{in}, i}-\sum \dot{\mathrm{m}}_{\mathrm{out}, i} h_{\mathrm{e}, i}}{V_{\mathrm{ch} \_ \text {mix }}}-\frac{\dot{V}_{\mathrm{ch} \_ \text {mix }}}{V_{\mathrm{ch} \_ \text {mix }}}\left(\sum\left[X_{i}\right] \bar{h}_{i}\right)-\sum\left[\dot{X}_{i}\right] \bar{h}_{i}+P_{\mathrm{ch} \_ \text {mix }} \sum\left[\dot{X}_{i}\right] / \sum\left[X_{i}\right]}{\sum\left[X_{i}\right] C_{\mathrm{p}, i}\left(T_{\mathrm{ch} \_ \text {mix }}\right)-P_{\text {ch_mix }} / T_{\text {ch_mix }}} \\
& \dot{P}_{\text {chamber }}=\frac{1}{V_{\text {chamber }}}\left(\frac{\dot{m}_{\text {chamber }}}{M_{\text {mix }}} R T_{\text {chamber }}+R \dot{T}_{\text {chamber }} \frac{m_{\text {chamber }}}{M_{\text {mix }}}-P_{\text {chamber }} \dot{V}_{\text {chamber }}\right)
\end{aligned}
$$

where the subscript $i$ refers to species $i$ containing in the post-combustion mixture (from the chemical reaction, the sufficient combustion assumption and also for simplifying the analysis, it is assumed that there are two species in the post-combustion mixture, i.e., $\mathrm{CO}_{2}$ and $\mathrm{H}_{2} \mathrm{O}$ ); the subscript chamber stands for the scroll expander center, the side and the exhaust chambers, $\dot{m}_{\mathrm{in}}=0$ for the side and exhaust chambers, and $\dot{m}_{\text {out }}=0$ for the center and side chambers; $M_{\text {mix }}$ is the average molecular mass of the post-combustion mixture, $M_{\text {mix }}=30.25 \mathrm{~g} / \mathrm{mol}$.

The methodology of the proposed feasibility study is described as follows. Firstly, the exhaust discharge port working conditions of a real vehicle gasoline engine system are analysed from the actual measurement data. Figure 3 shows the measurement data of post-combustion gas pressures, temperatures and mass flow rates. From Figure 3, it can be seen that the ranges of the gas pressures and temperatures at the exhaust discharging port are within the ranges of about $1.2 \times 10^{5} \mathrm{~Pa}$ to $1.7 \times 10^{5} \mathrm{~Pa}$ and $600 \mathrm{~K}$ to $1200 \mathrm{~K}$, respectively. The average values of gas pressures and temperatures shown in Figure 3, i.e., $1.30 \times 10^{5} \mathrm{~Pa}$ and $947.50 \mathrm{~K}$, are chosen as the pressure and temperature references of the supply working conditions of energy recycling system for the simulation study. Secondly, the input mass flow rates of the scroll expander are simulated via the developed exhaust recycling system model. Then the quantitative analysis of the simulated results against the measurement data of the mass flow rates at the discharge port of the engine system is studied, which indicates that how much exhaust flow can be recycled. From Figure 3, the average value of the measured mass flow rate at the engine system discharging port is obtained, i.e., $5.73 \times 10^{-2} \mathrm{~kg} / \mathrm{s}$, which is used as the flow reference in the following feasibility study. In addition, it should be mentioned that, because the pressure 
reference $\left(1.30 \times 10^{5} \mathrm{~Pa}\right)$ is quite close to the atmosphere, the over-expansion of the scroll expander using the reference as a supply pressure can happen in some situations. This has a negative effect on the expander's operation, i.e., the back-flow via the outlet of the expander and then the reduction of the expander generated torque, and thus this phenomenon will be studied in Section 3.2.

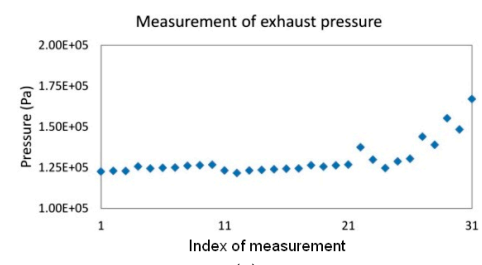

(a)

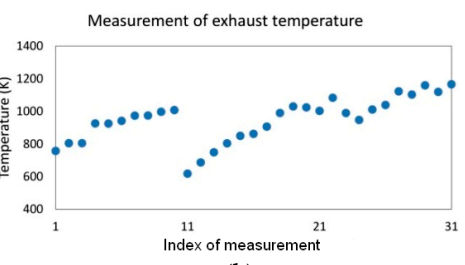

(b)

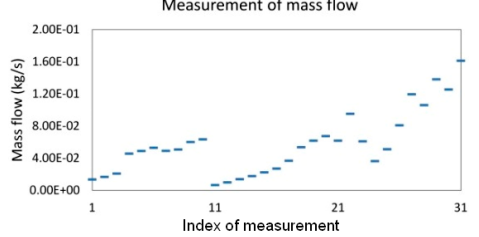

(c)

Figure 3. The actual measurement data from a discharge port of an internal combustion gasoline engine system: (a) exhaust pressures; (b) exhaust temperatures; and (c) exhaust mass flow rates.

Four groups of experiments at the authors' laboratory were conducted as a way of obtaining the measured data of the mass flow rate of scroll expander and then comparing to the flow reference $\left(5.73 \times 10^{-2} \mathrm{~kg} / \mathrm{s}\right)$. Figure 4 shows a schematic diagram of the test rig setup. A scroll expander (modified from a Sanden TRS09 scroll compressor) and a PMSG (GL-PMG 1000, Ginlong Technologies, Ningbo, China) are employed to assemble the test rig. A pressure regulator is used to set the input supply pressures for the scroll expander operation. A resistance circuit is connected to the PMSG output. In the test, compressed air at ambient temperature $(293 \mathrm{~K})$ rather than post-combustion gas is used as the input working medium, due to the limitations of the laboratory. The working conditions for the four group tests and the test results are given in Table 1. The electrical generator load was set at $22 \mathrm{ohm}$ in each phase. From the test, it is found that the supply pressure is one of the main factors that determines the mass flow rate of the scroll expander and the power output while the generator load resistor remains constant. From Table 1, the lower supply pressure results in the lower mass flow rate and in turn the lower expander power output while the supply temperature is kept unchanged. From Table 1, when the supply air pressure of the scroll expander reduces from $3.75 \times 10^{5} \mathrm{~Pa}$ to $2.50 \times 10^{5} \mathrm{~Pa}$, the measured mass flow rate is reduced from $7.65 \times 10^{-3} \mathrm{~kg} / \mathrm{s}$ to $3.15 \times 10^{-3} \mathrm{~kg} / \mathrm{s}$, which is around from $13.4 \%$ to $5.5 \%$ of the flow reference value $\left(5.73 \times 10^{-2} \mathrm{~kg} / \mathrm{s}\right)$. It is noticed that the scroll expander cannot start rotating properly when the supply pressure is at the pressure reference $\left(1.3 \times 10^{-5} \mathrm{~Pa}\right)$. Also, in the four groups of experiments (Table 1), after the air temperature at the scroll expander outlet reaches the steady state, the air temperature at the outlet can drop up to maximum $31 \mathrm{~K}$ compared to the inlet temperature.

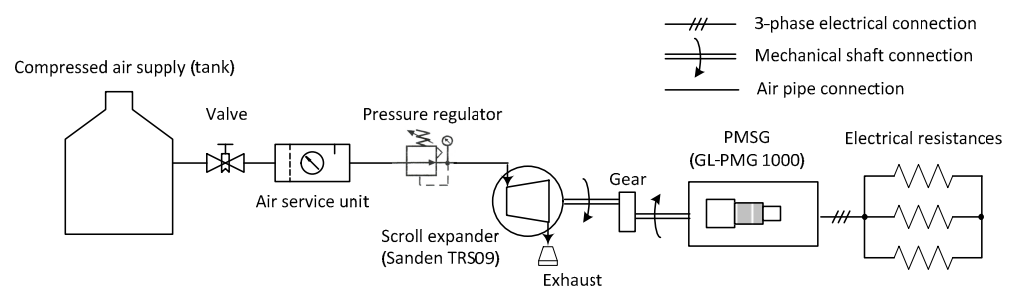

Figure 4. Schematic diagram of the test rig setup in the laboratory. 
Table 1. The four groups of experimental tests at the Warwick laboratory.

\begin{tabular}{|c|c|c|}
\hline Group No. & Working Condition Settings & Steady-state Test Results of the Scroll Expander \\
\hline 1st test & $\begin{array}{l}\text { supply pressure } 3.75 \times 10^{5} \mathrm{~Pa} \text {, } \\
\text { supply temperature } 293 \mathrm{~K}\end{array}$ & $\begin{array}{c}\text { mass flow rate } 7.65 \times 10^{-3} \mathrm{~kg} / \mathrm{s} \text {, power output } 385.1 \mathrm{~W} \text {, } \\
\text { outlet temperature } 262 \mathrm{~K}\end{array}$ \\
\hline 2nd test & $\begin{array}{l}\text { supply pressure } 3.50 \times 10^{5} \mathrm{~Pa} \text {, } \\
\text { supply temperature } 293 \mathrm{~K}\end{array}$ & $\begin{array}{c}\text { mass flow rate } 6.68 \times 10^{-3} \mathrm{~kg} / \mathrm{s} \text {, power output } 327.3 \mathrm{~W} \text {, } \\
\text { outlet temperature } 265 \mathrm{~K}\end{array}$ \\
\hline 3rd test & $\begin{array}{l}\text { supply pressure } 3.00 \times 10^{5} \mathrm{~Pa} \text {, } \\
\text { supply temperature } 293 \mathrm{~K}\end{array}$ & $\begin{array}{c}\text { mass flow rate } 4.74 \times 10^{-3} \mathrm{~kg} / \mathrm{s} \text {, power output } 221.3 \mathrm{~W} \text {, } \\
\text { outlet temperature } 271 \mathrm{~K}\end{array}$ \\
\hline 4th test & $\begin{array}{l}\text { supply pressure } 2.50 \times 10^{5} \mathrm{~Pa} \text {, } \\
\text { supply temperature } 293 \mathrm{~K}\end{array}$ & $\begin{array}{c}\text { mass flow rate } 3.15 \times 10^{-3} \mathrm{~kg} / \mathrm{s} \text {, power output } 125.9 \mathrm{~W} \text {, } \\
\text { outlet temperature } 280 \mathrm{~K}\end{array}$ \\
\hline
\end{tabular}

Additional tests are conducted in the laboratory. The test rig and the machine used are the same as shown in Figure 4. The tests are implemented by setting the input supply pressures at different values $\left(2.50 \times 10^{5} \mathrm{~Pa}, 2.75 \times 10^{5} \mathrm{~Pa}, 3.00 \times 10^{5} \mathrm{~Pa}\right.$ and $\left.3.25 \times 10^{5} \mathrm{~Pa}\right)$ and then gradually changing the scroll expander shaft rotation speeds. Figure 5 shows the experimental test results of the shaft torques and the rotation speeds of the scroll expander at different supply pressure conditions. From Figure 5, considering compressed air as working medium, the mechanical characteristics of the unmodified scroll expander can be studied.

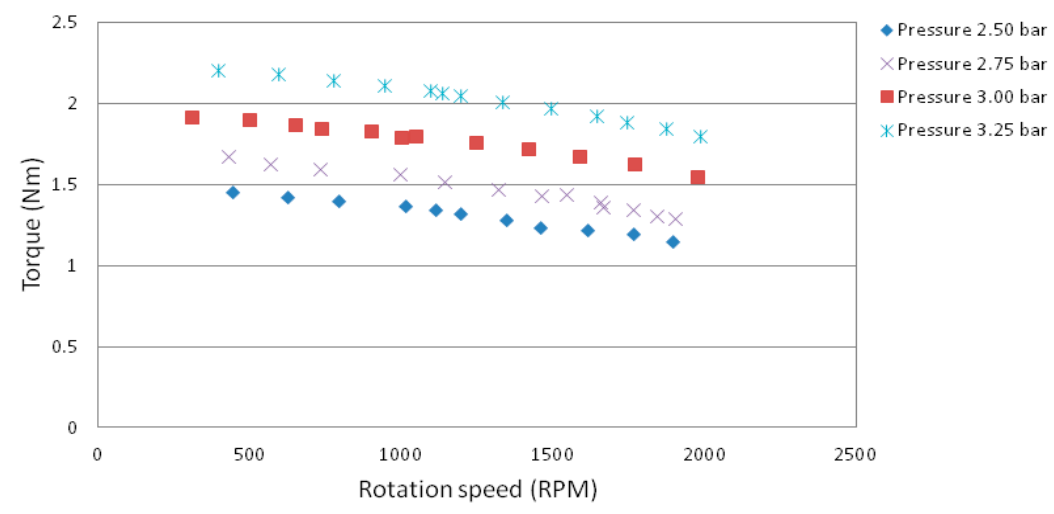

Figure 5. Experimental results of the unmodified scroll expander shaft torques and rotation speeds at different pressure conditions.

Assuming that compressed air and post-combustion mixture are the working media, respectively, the simulation study by using the developed exhaust energy recycling model is conducted. In the simulation, the parameters for the scroll expander model and the PMSG model are taken from the machines used in the experimental tests. The available parameters are shown in Table 2 and the unknown parameters can be obtained by using the evolutionary computation method with the experimental test data (refer to [33]).

The initial simulation study indicates that, if the supply pressure remains and the supply temperature increases from $293 \mathrm{~K}$ to the temperature reference $(947.50 \mathrm{~K})$, the simulated mass flow rate will get smaller. For instance, if the supply pressure remains at $2.5 \times 10^{5} \mathrm{~Pa}$ using compressed air as working medium (as in the experimental tests), the mass flow rate will drop more than $5.0 \times 10^{-4} \mathrm{~kg} / \mathrm{s}$ from $3.15 \times 10^{-3} \mathrm{~kg} / \mathrm{s}$. Also, as described in the experimental tests, the scroll expander cannot start rotating properly at the pressure reference $\left(1.3 \times 10^{5} \mathrm{~Pa}\right)$. Thus, it is not suitable to use the scroll expander with the original structure for exhaust recycling work. Therefore, modifications of the mechanical structure and dimensions of the scroll expander should be considered to achieve relatively high exhaust energy recovery rates. 
Table 2. The parameters of the used scroll expander and the permanent magnet synchronous generator (PMSG).

\begin{tabular}{ccc}
\hline Parameters & Values of Parameters & Unit \\
\hline Molecular mass of air & 28.97 & $\mathrm{~g} / \mathrm{mol}$ \\
Slope of radius of scroll curvature & 0.003183 & - \\
Orbit of the original moving scroll & 5.8 & $\mathrm{~mm}$ \\
Thicknesses of the moving and fixed scrolls & 4.5 & $\mathrm{~mm}$ \\
Heights of the moving and fixed scrolls & 33.3 & $\mathrm{~m}^{2}$ \\
Effective inlet area & $1.493 \times 10^{-4}$ & $\mathrm{~m}^{2}$ \\
Effective outlet area & $4.531 \times 10^{-4}$ & $\mathrm{~m}^{3}$ \\
Ideal gas constant & $4.1 \times 10^{-3}$ & $\mathrm{~J} /\left(\mathrm{mol}^{-3} \mathrm{~K}\right)$ \\
Molar mass of air & 8.314 & $\mathrm{~g} / \mathrm{mol}^{-3}$ \\
Total controlled volume of the scroll expander & 28.97 & $\mathrm{ohm}$ \\
Resistance of the stator windings & 6 & $\mathrm{mH}$ \\
Inductance on the $d$ axis & 17.5 & $\mathrm{mH}$ \\
Inductance on the $q$ axis & 17.5 & $\mathrm{~Wb}$ \\
Magnetic flux induced by magnets & 0.44 & - \\
Gear transmission ratio & 7.5 & $\mathrm{Nm}$ \\
Static friction of the scroll expander & 0.318 & $\mathrm{Nm}$ \\
Static friction of the gear & 0.213 & $\mathrm{kgm}$ \\
\hline Inertia of the whole energy recycling system & 0.002 &
\end{tabular}

\subsection{Evaluation on Recovering Exhaust Energy with Structure Modified Scrolls}

A few considered approaches to improve the scroll expander structure for better exhaust recycling trials are studied in this section. The study for enhancing the input mass flow rate of the exhaust recovery system includes increasing the scroll expander inlet port dimensions, modifying the scroll structure to lead to the scroll center chamber volume enlargement, and varying the scroll expander geometry parameters. The corresponding simulation study is conducted and the same methodology of the proposed feasibility study described in Section 3 is implemented. A quantitative analysis of using the structurally modified scrolls for the recycling work is reported. The aim of the study is to increase the scroll expander intake mass flow rate to close to the flow reference (i.e., $5.73 \times 10^{-2} \mathrm{~kg} / \mathrm{s}$ ) as much as possible, which will lead to more exhaust energy being recovered. The post-combustion mixture is used as working medium for the simulation study in this section and thus the properties of the mixture described in Section 3 is adopted.

\subsubsection{Case I-Increasing the Scroll Expander Intake Port}

One straightforward way to increase the input mass flow rate of the exhaust energy recycling system is to enhance the flow rate of the scroll expander intake mass flow rate. This can be naturally accomplished by modifying the scroll expander intake port to have a larger diameter. From the structure of the scroll expander, the inlet port of scroll expander lies in the center of the fixed scroll plate, and its size can only be extended in a finite range due to the scroll center chamber's limited cross-section area (Figure 6). The inlet area cannot exceed the minimum value of the cross-section area of the center chamber; otherwise, the supply compressed air will directly go into the side chambers during the expander operation. The original scroll inlet area is $1.493 \times 10^{-4} \mathrm{~m}^{2}$ (Table 2) and the minimum value of the center chamber cross-section area is about $4.54 \times 10^{-4} \mathrm{~m}^{2}$ (Figure 6). Thus, the scroll expander intake can be modified to roughly maximum three times the original open area. The descriptions of parameter settings and working conditions for the six simulation groups (the 1st-6th groups) are shown in Table 3 and the electrical generator load always sets $120 \mathrm{ohm}$ on each phase, which are prepared for implementing the analysis of exhaust recycling potentials to this case study. 


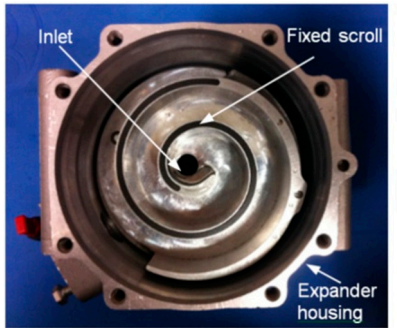

(a)

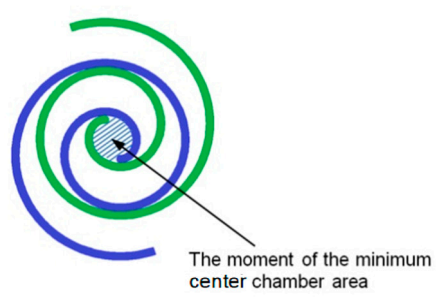

(b)

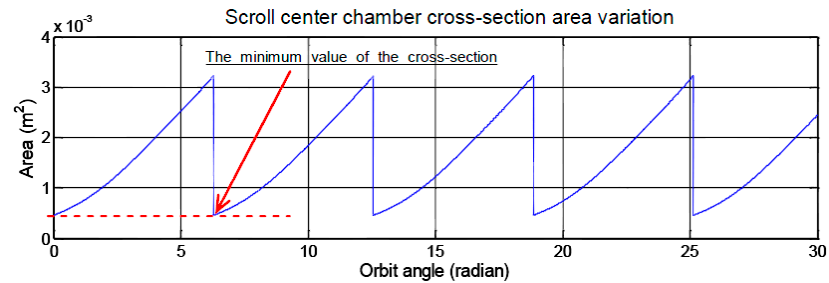

(c)

Figure 6. The scroll expander inlet and the center chamber (modified from Sanden TRS09). (a) The expander inlet; (b) the schematic diagram of the moment of the minimum center chamber; and (c) the simulation study of the center chamber cross-section area variation.

Table 3. Parameter settings and working conditions for the simulation groups (the 1st-6th groups).

\begin{tabular}{clc}
\hline Group No. & Working Conditions & Parameter Settings \\
\hline \multirow{2}{*}{1 st } & $\begin{array}{c}\text { supply pressure } 2.0 \times 10^{5} \mathrm{~Pa} \\
\text { supply temperature } 947.50 \mathrm{~K}\end{array}$ & $\begin{array}{c}\text { the original open area of scroll } \\
\text { expander inlet }\end{array}$ \\
\hline \multirow{2}{*}{ 2nd } & $\begin{array}{c}\text { supply pressure } 1.5 \times 10^{5} \mathrm{~Pa} \\
\text { supply temperature } 947.50 \mathrm{~K}\end{array}$ & $\begin{array}{c}\text { the original open area of scroll } \\
\text { expander inlet }\end{array}$ \\
\hline \multirow{2}{*}{ 3rd } & $\begin{array}{c}\text { supply pressure } 1.3 \times 10^{5} \mathrm{~Pa} \\
\text { supply temperature } 947.50 \mathrm{~K}\end{array}$ & $\begin{array}{c}\text { the original open area of scroll } \\
\text { expander inlet }\end{array}$ \\
\hline \multirow{2}{*}{ 4th } & $\begin{array}{c}\text { supply pressure } 2.0 \times 10^{5} \mathrm{~Pa} \\
\text { supply temperature } 947.50 \mathrm{~K}\end{array}$ & $\begin{array}{c}\text { three times of the open area of } \\
\text { original scroll inlet }\end{array}$ \\
\hline \multirow{2}{*}{ 5th } & $\begin{array}{l}\text { supply pressure } 1.5 \times 10^{5} \mathrm{~Pa} \\
\text { supply temperature } 947.50 \mathrm{~K}\end{array}$ & $\begin{array}{c}\text { three times of the open area of } \\
\text { original scroll inlet }\end{array}$ \\
\hline \multirow{2}{*}{ 6th } & $\begin{array}{l}\text { supply pressure } 1.3 \times 10^{5} \mathrm{~Pa} \\
\text { supply temperature } 947.50 \mathrm{~K}\end{array}$ & $\begin{array}{c}\text { three times of the open area of } \\
\text { original scroll inlet }\end{array}$ \\
\hline
\end{tabular}

Figure 7 shows the simulation results for the 1st group. From Figure 7, the average mass flow rate is about $1.99 \times 10^{-3} \mathrm{~kg} / \mathrm{s}$, i.e., only $3.5 \%$ of the flow reference. After the post-combustion gas expansion in the side chambers, at the steady state the initial pressure in each cycle of the exhaust chamber $\left(1.11 \times 10^{5} \mathrm{~Pa}\right.$, Figure 7$)$ is slightly higher than atmospheric; and its temperature drops with the expansion process in the side chambers. From the simulated results, it is seen that the trend for this case study is similar to that in Section 3, that is, at the same supply temperatures and the same electrical loads, the higher supply pressure leads to a higher scroll rotor speed and more scroll intake mass flow rate. It is reasonable to compare the simulation results between the 1 st and the 4 th groups, the 2 nd and the 5th groups, respectively, because the expander is operated at the same working conditions; from the comparisons, it is found that increasing the size of the expander intake and the mass flow improvement does not have a linear relationship - the mass flow rate only has a slight difference compared to the previous situations: the mass flow rate increases $3.21 \%$ in the 4th group compared to the result from 1 st groups and $3.88 \%$ in the 5 th group compared to the result from the 2nd group. From the simulation study, in the 3rd and 6th group the scroll expander cannot start rotation properly 
due to the low air supply pressure $\left(1.3 \times 10^{5} \mathrm{~Pa}\right)$. In addition, overexpansion can happen when the supply pressures are $1.5 \times 10^{5} \mathrm{~Pa}$. Thus, the exhaust of the scroll expander could flow backwards via the outlet of the scroll expander at such condition, and this definitely has a negative effect of the recycling work [20,32]. From the above, if expanding the intake port of the scroll expander only, the modified scroll expander is still not suitable for the engine exhaust energy recycling work and the further modification of the scroll expander needs to be considered.

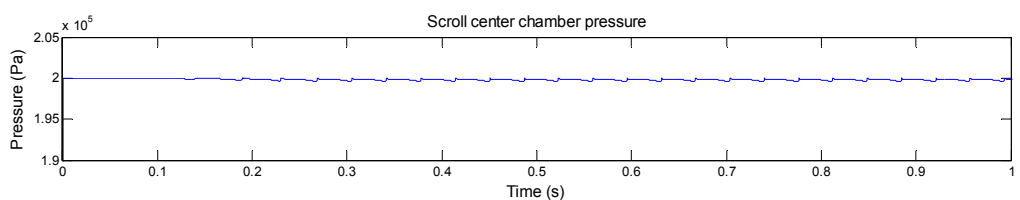

(a)

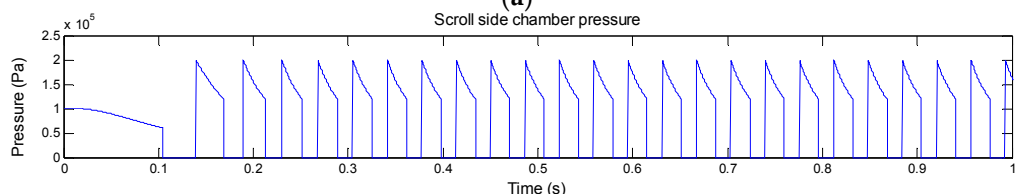

(b)

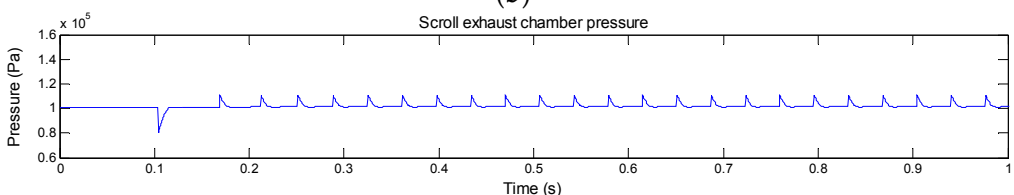

(c)

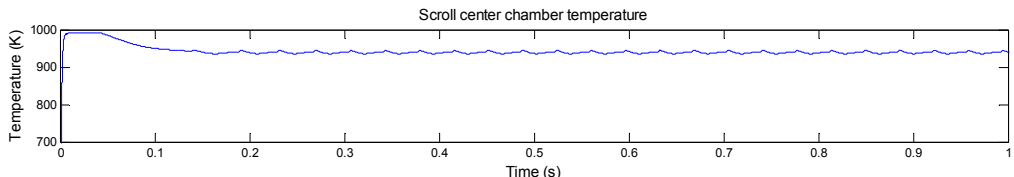

(d)

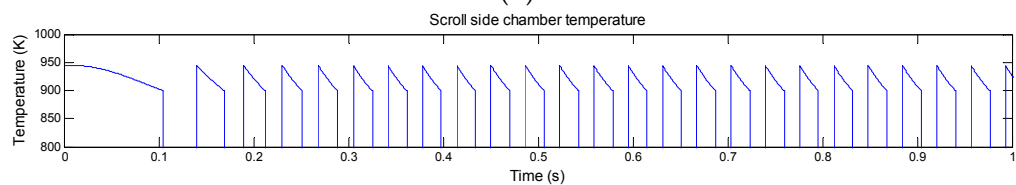

(e)

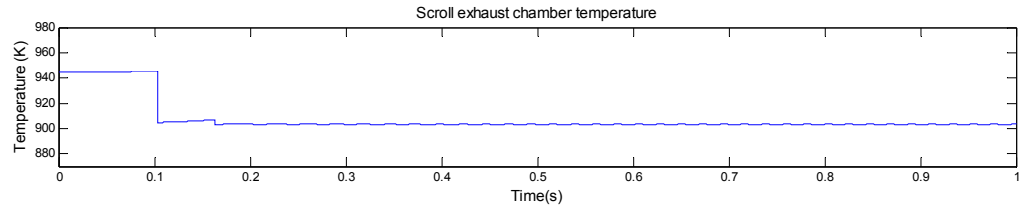

(f)

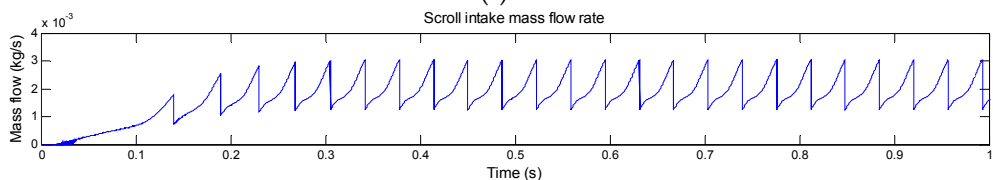

(g)

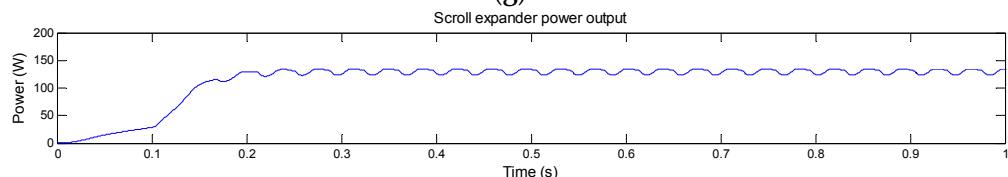

(h)

Figure 7. Simulation results for the 1st group: (a) the center chamber pressure; (b) the side chamber pressure; (c) the exhaust chamber pressure; (d) the center chamber temperature; (e) the side chamber temperature; (f) the exhaust chamber temperature; $(\mathrm{g})$ the intake mass flow rate; and (h) the expander output power. 


\subsubsection{Case II-Enlarging Volume of the Scroll Expander Center Chamber}

The further proposed modification of the scroll expander geometrical structure is made by the following steps:

(1) the first circle wrap of the original fixed and moving scrolls is removed to increase the volume of the center chamber of the scroll expander (Figure 8);

(2) increasing the inlet port size further to get more exhaust gas flow into the engine exhaust recycling system (in this case, the open area of the intake port is twelve times the original intake and the reason for this is that the minimum value of the newly formed center chamber cross-section area needs to be considered, which is similar to the descriptions in the first paragraph of Section 3.2.1.)

(3) extending one new circle scroll wrap from both the fixed and moving scroll ending points in order to maintain the original number of scroll wraps for these two scrolls.

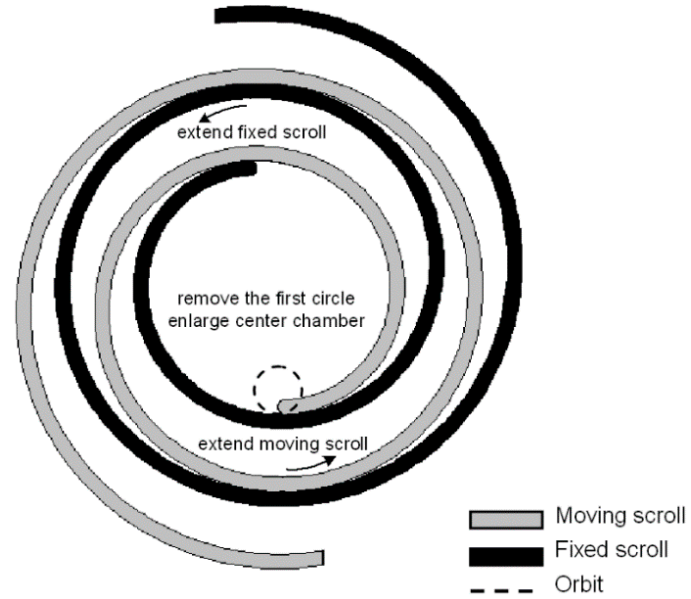

Figure 8. Schematic diagram of a structurally improved scroll expander (modified by the steps of Case II).

Based on the above modifications, some parameter setting changes of the original scroll expander thermodynamic model must be reformed, including increasing the total controlled volume and the outlet area of the scroll expander and resetting the initial volume of scroll center chamber. Figure 8 shows the two scroll structures after the proposed modifications. The four simulation groups (the 7th-10th groups) for simulation study are carried out and the descriptions of parameter settings and working conditions are listed in Table 4.

Table 4. Parameter settings and working conditions for the simulation group (the 7 th-10th groups).

\begin{tabular}{clc}
\hline Group No. & Working Conditions & Parameter Settings \\
\hline 7th & $\begin{array}{c}\text { supply pressure } 2.0 \times 10^{5} \mathrm{~Pa} \\
\text { supply temperature } 947.50 \mathrm{~K}\end{array}$ & $\begin{array}{c}\text { The expander modified by the above steps, twelve } \\
\text { times of the open area of original inlet }\end{array}$ \\
\hline 8th & $\begin{array}{c}\text { supply pressure } 1.7 \times 10^{5} \mathrm{~Pa} \\
\text { supply temperature } 947.50 \mathrm{~K}\end{array}$ & $\begin{array}{c}\text { The expander modified by the above steps, twelve } \\
\text { times of the open area of original inlet }\end{array}$ \\
\hline 9th & $\begin{array}{c}\text { supply pressure } 1.5 \times 10^{5} \mathrm{~Pa} \\
\text { supply temperature } 947.50 \mathrm{~K}\end{array}$ & $\begin{array}{c}\text { The expander modified by the above steps, twelve } \\
\text { times of the open area of original inlet }\end{array}$ \\
\hline \multirow{2}{*}{ 10th } & $\begin{array}{c}\text { supply pressure } 1.3 \times 10^{5} \mathrm{~Pa} \\
\text { supply temperature } 947.50 \mathrm{~K}\end{array}$ & $\begin{array}{c}\text { The expander modified by the above steps, twelve } \\
\text { times of the open area of original inlet }\end{array}$ \\
\hline
\end{tabular}

Figure 9 shows the simulation results for the 7th group. The electrical generator load is set at $120 \mathrm{ohm}$ on each phase, which is the same as the simulation study for the 1st group. From the 
comparison of the results at steady states shown in Figures 4 and 6 it is seen that, with the same working conditions (supply and load), in each cycle the initial pressure of the exhaust chamber in Figure $9\left(1.32 \times 10^{5} \mathrm{~Pa}\right)$ is higher than that in Figure $7\left(1.11 \times 10^{5} \mathrm{~Pa}\right)$. With the further simulation studies, it is found that overexpansion does not happen at the supply pressures of $1.7 \times 10^{5} \mathrm{~Pa}$ and $1.5 \times 10^{5} \mathrm{~Pa}$ but happens at the supply pressure of $1.3 \times 10^{5} \mathrm{~Pa}$. From Figure 9, the average scroll intake mass flow rate increases up to $4.05 \times 10^{-3} \mathrm{~kg} / \mathrm{s}$, which is higher than the simulation result of the $1^{\text {st }}$ group $\left(1.99 \times 10^{-3} \mathrm{~kg} / \mathrm{s}\right)$. Therefore, after the modifications described in Case II, the geometrical structure changes of the scroll expander lead to an increase in mass flow rate. Thus, the structure modified scroll expander is more suitable to operate under low supply pressure conditions, e.g., $1.5 \times 10^{5} \mathrm{~Pa}$.

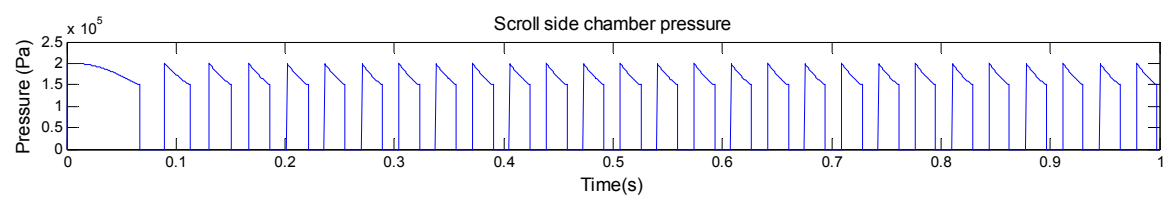

(a)

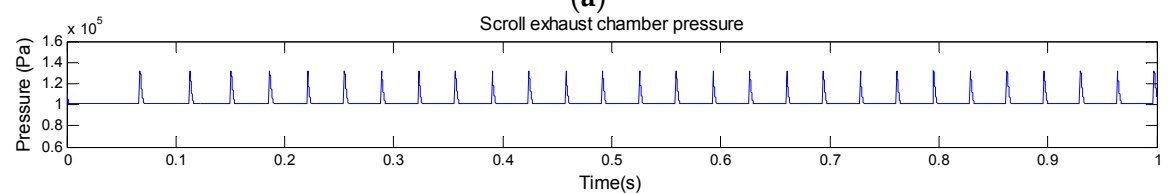

(b)

Scroll side chamber temperature

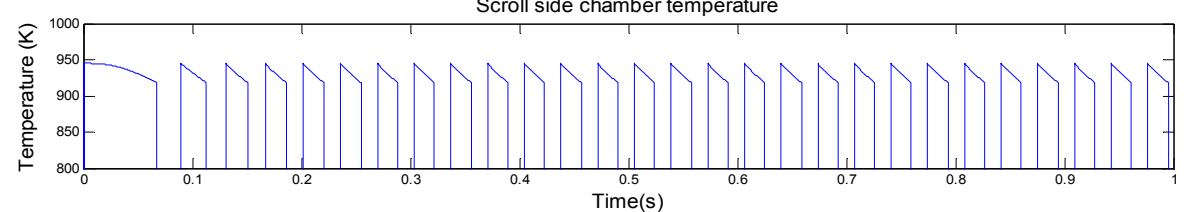

(c)

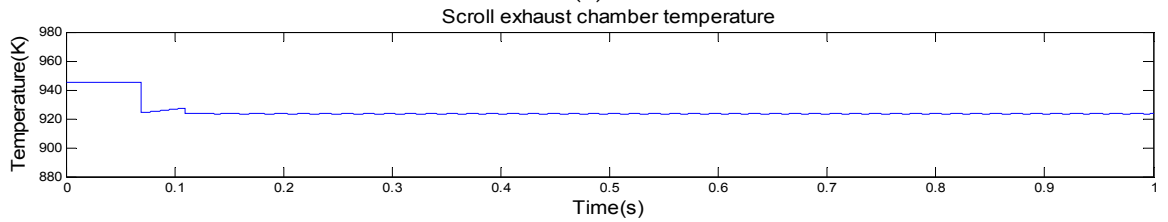

(d)

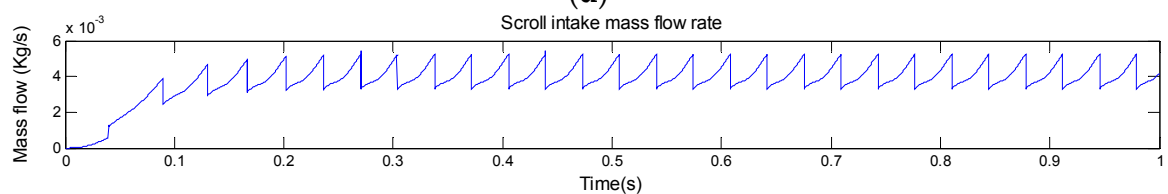

(e)

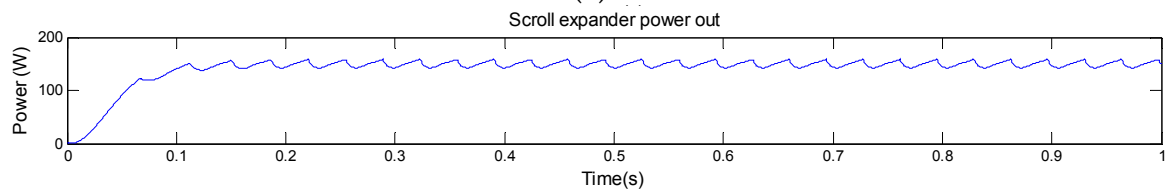

(f)

Figure 9. Simulation results for the 7th group: (a) the side chamber pressure; (b) the exhaust chamber pressure; (c) the side chamber temperature; (d) the exhaust chamber temperature; (e) the intake mass flow rate; and (f) the expander output power.

Figure 10 presents the simulation results for the 7th group when the electrical resistance load varies. From Figure 10, the maximum mass flow rate of the post-combustion mixture gas reaches $6.68 \times 10^{-3} \mathrm{~kg} / \mathrm{s}$; the scroll expander shaft power has a peak value of $164.5 \mathrm{~W}$; after the scroll expander transient process, the scroll expander power output can be maintained around $162 \mathrm{~W}$. Thus, if the 
working conditions are set as in the 7th group (Table 4), a maximum $11.7 \%$ of the engine exhaust flow (the flow reference is $5.73 \times 10^{-2} \mathrm{~kg} / \mathrm{s}$ ) will enter the energy recycling system. From the above analysis, by enlarging the inlet port and the center chamber, the modifications suggested in Case II will allow scroll expander intake flow and exhaust recovery rate improvements within a certain range.

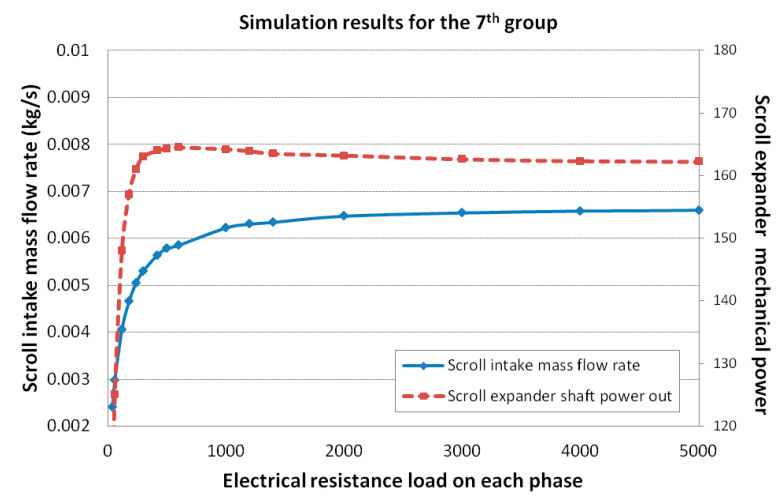

Figure 10. Simulation results for the 7th group with the varying electrical resistance loads.

\subsubsection{Case III—Modifying Scroll Geometry Parameters}

Although the utilization ratio of gasoline engine exhaust flow has been raised from the study of Cases I and II, the scroll expander operation is still weak when the supply pressure is set at the measured pressure reference $\left(1.30 \times 10^{5} \mathrm{~Pa}\right)$ and the overexpansion issue exists under such conditions. It is believed that there is a considerable range for further improvement of the exhaust recycle ratio by overcoming the overexpansion issue via modification of the scroll expander mechanical structure and geometrical parameters. Thus further modifications have been made by the below steps:

(1) keeping the modifications of the scroll expander from the steps of Case II;

(2) increasing the parameter of the moving scroll orbit radius to three times the original value of this parameter;

(3) according to the nature of the scroll geometry, the slope of the curvature radius $(k)$ to the moving and the fixed scrolls need to be recalculated, i.e., $k=\left(\alpha_{\mathrm{s}}+\delta_{\mathrm{s}}\right) / \pi$, where $\delta_{\mathrm{s}}$ is the thickness of the two scrolls (refer to [25]);

(4) adjusting the lengths of the two scroll wraps via the simulation study, to avoid the over-expansion problem.

After the first three steps of modifications in Case III, the volumes of the scroll expander chambers are varied. The total control volume of the scroll expander is also varied accordingly. The purpose of adjusting the scroll expander geometry parameters is to vary the expander side chamber expansion volumetric ratio (i.e., the ratio between the minimum and maximum values of the side chamber volume) to avoid the over-expansion and for accelerating the velocity of engine exhaust flow through the scroll mechanism. The simulation study for the four groups (the 11th 14th simulation groups) are implemented and the descriptions of working conditions and parameter settings are listed in Table 5 .

The simulation results for the 14th group after the scroll expander was modified by the first three steps of Case III are given in Figure 11, which consists of the moving scroll orbit angle in each cycle, the expander side chamber pressure, the expander intake mass flow rate and the expander power out respectively. The electrical generator load is set at $120 \mathrm{ohm}$ on each phase. The average intake mass flow rate of the scroll expander is improved to $3.45 \times 10^{-2} \mathrm{~kg} / \mathrm{s}$ and the scroll expander shaft power output can reach $423.0 \mathrm{~W}$. However, from Figure 11, with the supply pressure of $1.3 \times 10^{5} \mathrm{~Pa}$, it is seen that a slight overexpansion happens in the scroll side chamber. The scroll expander exhaust could flow backwards via the expander outlet and thus the generated workable torque from the expander can be reduced. Therefore, the lengths of the two scroll wraps need to be modified to shorten the scroll wrap 
from the ending point of each scroll. From the side chamber pressure shown in Figure 11, the moment when the side chamber pressure equals to the atmospheric pressure indicates the over-expansion start so the corresponding orbit angle marked with the red dotted line in Figure 11 gives the critical point to determine the scroll wrap length for the "perfect" expansion. In each cycle the crescent side chambers of the original expander exist from 0 to $1.1 \pi$ of the orbit angle (Figure 11) and now this is reduced by shortening the scroll wrap. The side chamber volume, pressure and temperature need to be recalculated based on the modelling equations described in Sections 2.2 and 3.

Table 5. Parameter settings and working conditions for the simulation group (the 11th-14th groups).

\begin{tabular}{clc}
\hline Group No. & \multicolumn{1}{c}{ Working Conditions } & Parameter Settings \\
\hline \multirow{2}{*}{ 11th } & $\begin{array}{l}\text { supply pressure } 2.0 \times 10^{5} \mathrm{~Pa} \\
\text { supply temperature } 947.50 \mathrm{~K}\end{array}$ & $\begin{array}{c}\text { the scroll expander modified by the steps } \\
\text { described in Case III }\end{array}$ \\
\hline \multirow{2}{*}{ 12th } & $\begin{array}{l}\text { supply pressure } 1.7 \times 10^{5} \mathrm{~Pa} \\
\text { supply temperature } 947.50 \mathrm{~K}\end{array}$ & $\begin{array}{c}\text { the scroll expander modified by the steps } \\
\text { described in Case III }\end{array}$ \\
\hline \multirow{2}{*}{ 13th } & $\begin{array}{l}\text { supply pressure } 1.5 \times 10^{5} \mathrm{~Pa} \\
\text { supply temperature } 947.50 \mathrm{~K}\end{array}$ & $\begin{array}{c}\text { the scroll expander modified by the steps } \\
\text { described in Case III }\end{array}$ \\
\hline \multirow{2}{*}{ 14th } & $\begin{array}{l}\text { supply pressure } 1.3 \times 10^{5} \mathrm{~Pa} \\
\text { supply temperature } 947.50 \mathrm{~K}\end{array}$ & $\begin{array}{c}\text { the scroll expander modified by the steps } \\
\text { described in Case III }\end{array}$ \\
\hline
\end{tabular}
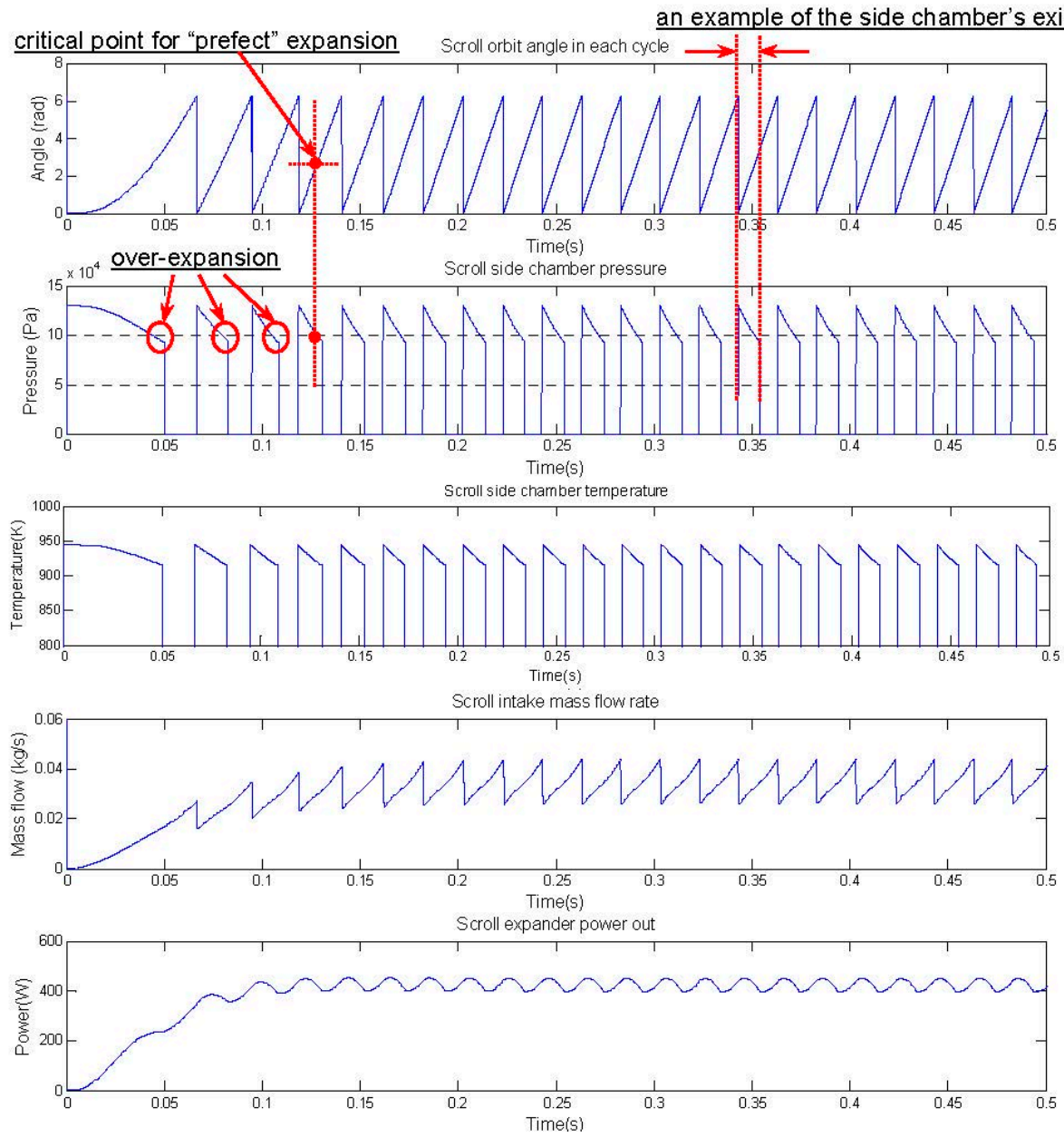

Figure 11. Simulation results for the 14th group (the scroll expander modified by the steps (1) and (2) of Case III). 
Figure 12 presents the simulation results after shortening the two scroll wrap lengths. The lengths of the moving and fixed scroll wraps are both shortened from 2.10 circles to 1.905 circles. A schematic diagram of the structure of modified scroll expander is shown in the left of Figure 12. From Figure 12, the pressure of post-combustion mixture in the expansion process is always higher than atmospheric and thus the overexpansion is avoided. The average intake mass flow rate of the scroll expander is at $3.53 \times 10^{-2} \mathrm{~kg} / \mathrm{s}$ and the expander shaft power output is $443.5 \mathrm{~W}$. Therefore, from the comparison of the simulation results in Figures 9 and 11 it is seen that, under the same working conditions with the proper adjustment of the length of scroll wraps, both the scroll expander intake mass flow rate and the useful expander shaft power output can be improved.

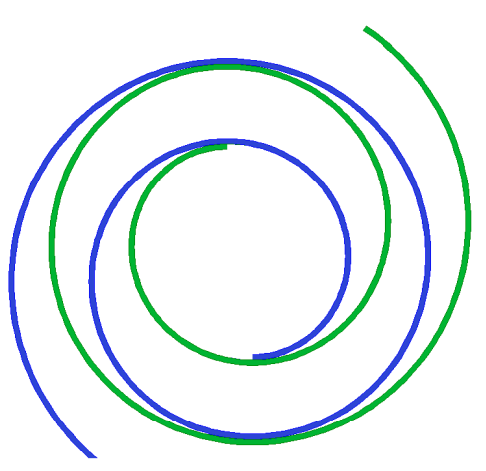

Schematic diagram of the scroll expander modified by the all steps of Case III
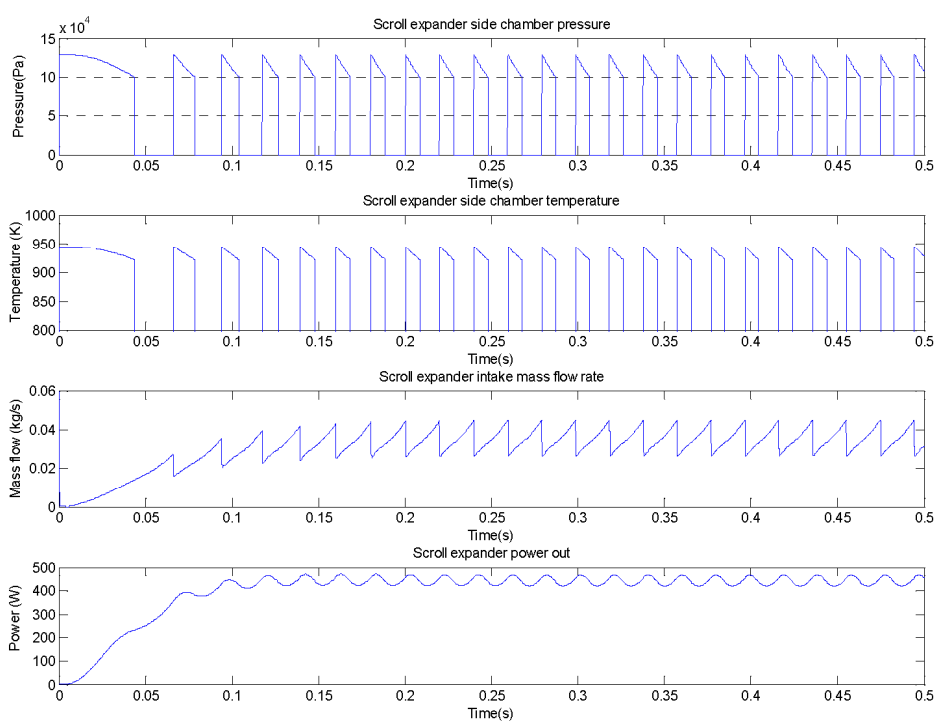

Figure 12. Simulation results for the 14th group (the scroll expander modified by the steps (1-3), and also (4) of Case III-adjusted the lengths of the scroll wraps).

Figure 13 shows the simulation results for the 14th group with varying electrical resistance loads. When the supply conditions are at the reference values (supply pressure $1.3 \times 10^{5} \mathrm{~Pa}$ and supply temperature $947.5 \mathrm{~K}$ ), the average steady mass flow rate to the expander intake can reach $5.38 \times$ $10^{-2} \mathrm{~kg} / \mathrm{s}$, or about $93.9 \%$ of the flow reference $\left(5.73 \times 10^{-2} \mathrm{~kg} / \mathrm{s}\right)$, which is a remarkable increase compared with the corresponding simulation results in Case I and II. Thus from the study of Case III, the gasoline engine exhaust energy recovery ratio can be dramatically raised. In Figure 13, the peak value of the scroll expander shaft power output is $461.5 \mathrm{~W}$ with a steady state output of around $425 \mathrm{~W}$. In practice, the results may be affected by the weight, friction and inertia changes associated with the scroll modifications.

Table 6 presents the summary of all the case studies of using the structurally modified scroll expander for the engine exhaust gas recycling application. It can be seen that the structurally modified scroll expander has the potential to be an energy transformer for recycling gasoline engine exhaust energy. In addition, because the geometric structure of the scroll expander (including the inlet area, the moving scroll orbit radius, the scroll curvature radius and the scroll wraps) is modified with the proposed modifications (i.e., Cases I, II and III), the baseplates for the moving and fixed scrolls and the volume of the scroll machine shell will be increased in dimension accordingly. 


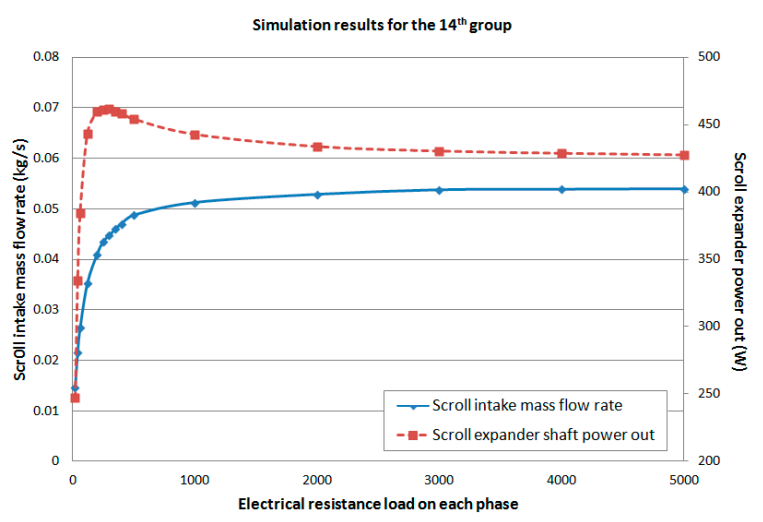

Figure 13. Simulation results for the 14th group with the varying electrical resistance loads.

Table 6. The summary of the all case studies in Section 3.2.

\begin{tabular}{|c|c|c|}
\hline Case No. & $\begin{array}{l}\text { Brief Descriptions of } \\
\text { Proposed Modifications }\end{array}$ & Summary of the Simulation Study \\
\hline Case I & Three times the open area of the original inlet & $\begin{array}{l}\text { With supply conditions at } 2.0 \times 10^{5} \mathrm{~Pa} \text { and } \\
947.50 \mathrm{~K}, 3.5 \% \text { of the flow reference obtained } \\
\text { (Figure } 7 \text { ), not suitable for the application. }\end{array}$ \\
\hline Case II & $\begin{array}{l}\text { Remove the first circle scroll wrap, expand } \\
\text { the inlet port to twelve times of the open area } \\
\text { of original inlet, and extend one new circle } \\
\text { scroll wrap from the ending point }\end{array}$ & $\begin{array}{l}\text { With supply conditions at } 2.0 \times 10^{5} \mathrm{~Pa} \text { and } \\
947.50 \mathrm{~K} \text {, maximum } 11.7 \% \text { of the flow } \\
\text { reference obtained (Figure 10), still not } \\
\text { suitable for the application. }\end{array}$ \\
\hline Steps $1 \& 2$ of Case III & $\begin{array}{l}\text { Keep the modifications in Case II, extend the } \\
\text { parameters of the moving scroll orbit radius } \\
\text { and the slope of scroll curvature radius }\end{array}$ & $\begin{array}{l}\text { With the exact required supply conditions } \\
\left.\text { (i.e., } 1.3 \times 10^{5} \mathrm{~Pa} \text { and } 947.50 \mathrm{~K}\right),>60 \% \text { of the } \\
\text { flow reference obtained (Figure } 11) \text {; over- } \\
\text { expansion exists (leading to back-flow) and } \\
\text { thus it need further modification. }\end{array}$ \\
\hline All steps of Case III & $\begin{array}{l}\text { Aside from Steps } 1 \& 2 \text { of Case III, take } \\
\text { further action, i.e., adjustment of the lengths } \\
\text { of the two scroll wraps via the simulation } \\
\text { study to avoid overexpansion (Figure 12) }\end{array}$ & $\begin{array}{l}\text { With the exact required supply conditions } \\
\left.\text { (i.e., } 1.3 \times 10^{5} \text { and } 947.50 \mathrm{~K}\right) \text {, maximum } 93.9 \% \\
\text { of the flow reference obtained (Figure } 13 \text { ); no } \\
\text { over-expansion issue; suitable for the exhaust } \\
\text { gas recycling application. }\end{array}$ \\
\hline
\end{tabular}

\section{Conclusions}

This paper presents a feasibility study for the recovery of exhaust energy from a vehicle gasoline engine system. From the study, the following conclusions are reached: (1) it is possible to recover energy from gasoline engine exhaust using scroll expander technology; (2) the scroll expander structure needs to be carefully designed for operation under low-pressure exhaust conditions; (3) the strategies for modification of the scroll expander structure were investigated and tested via simulation studies, from which suitable scroll expanders can be designed for engine exhaust energy recovery applications; (4) the critical conditions for overexpansion which can be avoided by altering the scroll wrap lengths are studied. From the study, under the engine exhaust conditions, i.e., $1.3 \times 10^{5} \mathrm{~Pa}$ and $947.50 \mathrm{~K}$, the original scroll expander cannot operate properly and the structurally improved scroll expander which is modified by the proposed Case III has the potential to produce over $400 \mathrm{~W}$ power output with over $90 \%$ of engine exhaust flow recycling.

Acknowledgments: The authors would like to thank the funding support from Engineering and Physical Sciences Research Council (EPSRC) UK (EP/J01043X/1, EP/K002228/1).

Author Contributions: All authors contributed to this work in collaboration. Xing Luo and Jihong Wang contributed to the system modelling, the simulation study and the writing of the manuscript. The research idea was proposed and guided by Jihong Wang and Hongming $\mathrm{Xu}$. Christopher Krupke was responsible for building the test rig and implementing the experiments with Xing Luo. 
Conflicts of Interest: The authors declare no conflict of interest.

\section{Nomenclature}

\begin{tabular}{|c|c|c|}
\hline$A_{\text {ori }}$ & Effect & ive open area of the orifice $\left(\mathrm{m}^{2}\right)$ \\
\hline & & {$[\underline{\gamma+1}]^{1 / 2}$} \\
\hline$C_{0}$ & $C_{0}=$ & $\left(\gamma M_{\mathrm{air}} / R\right)(2 /(\gamma+1)) \overline{\gamma-1}$ \\
\hline$C_{\mathrm{d}}$ & Disch & arge coefficient \\
\hline & & $\underline{\gamma+1}]^{1 / 2}$ \\
\hline$C_{\mathrm{k}}$ & $C_{\mathrm{k}}=$ & $(2 / \gamma-1)((\gamma+1) / 2) \overline{\gamma-1}$ \\
\hline$C_{\mathrm{p}, \text { air }}(T)$ & Specif & ic heat of air at pressure $T\left(\mathrm{~kJ} \cdot \mathrm{K}^{-1} \cdot \mathrm{kg}^{-1}\right)$ \\
\hline$c_{\mathrm{r}}$ & $c_{\mathrm{r}}=[$ & $2 /(\gamma+1)]^{\gamma /(\gamma-1)}$ \\
\hline$h$ & Specif & ic enthalpy of air $(\mathrm{J} / \mathrm{kg})$ \\
\hline $\bar{h}$ & Specif & ic enthalpy of the air on a molar basis $(\mathrm{J} / \mathrm{mol})$ \\
\hline$h_{\mathrm{in}, i}$ & Specif & ic enthalpy of species $i$ from the inlet of scroll expander $(\mathrm{J} / \mathrm{kg})$ \\
\hline$h_{\text {out }, i}$ & Specif & ic enthalpy of species $i$ to the outlet of scroll expander $(\mathrm{J} / \mathrm{kg})$ \\
\hline$i$ & Curre & nt in the different axes for the PMSG modelling (Ampere) \\
\hline$J_{\text {total }}$ & The $\mathrm{w}$ & hole energy recycling system's moment of inertia $\left(\mathrm{kg} \cdot \mathrm{m}^{2}\right)$ \\
\hline$k$ & Slope & of the curvature radius \\
\hline$K_{\mathrm{fs}}$ & Coeffi & cient of the scroll expander viscous friction \\
\hline$K_{\text {fgen }}$ & Coeffi & cient of the PMSG viscous friction \\
\hline$K_{\text {fgear }}^{0}$ & Coeffi & cient of the gear viscous friction \\
\hline$K_{S-C 1} S\left(\omega_{s}\right)$ & Comb & ined effect on torque from the scroll expander static and Coulomb frictions \\
\hline$K_{S-C 2} S\left(\omega_{\mathrm{g}}\right)$ & $\begin{array}{l}\text { Comb } \\
\text { PMSC }\end{array}$ & $\begin{array}{l}\text { ined effect on torque from the static and Coulomb frictions of the } \\
\text { and gear }\end{array}$ \\
\hline$L_{\mathrm{d}}, L_{\mathrm{q}}$ & Induc & tances of $d$ axis and $q$ axis respectively $(\mathrm{H})$ \\
\hline$M_{\text {air }}$ & Molar & mass of air, $M_{\text {air }}=28.8 \mathrm{~g} / \mathrm{mol}$ \\
\hline$M_{\text {mix }}$ & Avera & ge molar mass of the post-combustion mixture $(\mathrm{g} / \mathrm{mol})$ \\
\hline$m$ & Mass & of the air $(\mathrm{kg})$ \\
\hline$\dot{m}$ & Mass & flow rate of the air $(\mathrm{kg} / \mathrm{s})$ \\
\hline$\dot{m}_{\mathrm{in}, i}$ & Mass & flow rate for species $i$ from the inlet of scroll expander $(\mathrm{kg} / \mathrm{s})$ \\
\hline$\dot{m}_{\text {out }, i}$ & Mass & flow rate for species $i$ to the outlet of scroll expander $(\mathrm{kg} / \mathrm{s})$ \\
\hline$n_{\mathrm{s}}$ & Numb & ers of scroll wraps \\
\hline$p_{\mathrm{g}}$ & Numk & er of the pole pairs in the PMSG \\
\hline$P$ & Air pr & essure $(\mathrm{Pa})$ \\
\hline$P_{\text {ch_mix }}$ & The $\mathrm{p}$ & ost-combustion mixture pressure inside the scroll expander chamber $(\mathrm{Pa})$ \\
\hline$P_{\mathrm{d}}$ & Down & stream pressure of the orifice $(\mathrm{Pa})$ \\
\hline$P_{\mathrm{u}}$ & Upstr & eam pressure of the orifice $(\mathrm{Pa})$ \\
\hline$\hat{P}$ & Presst & are difference between the adjacent chambers of the scroll expander $(\mathrm{Pa})$ \\
\hline$r_{\mathrm{s}}$ & Radiu & $\mathrm{s}$ of the orbit relevant to the moving scroll motion (m) \\
\hline$R$ & Ideal & gas constant $\left(\mathrm{J} \cdot \mathrm{K}^{-1} \cdot \mathrm{kg}^{-1}\right)$ \\
\hline$R_{\mathrm{g}}$ & Resist & ance of the PMSG stator windings (ohm) \\
\hline$S\left(\omega_{\mathrm{s}}\right)$ & Comb & ination effect description on torque from the scroll static and Coulomb frictions \\
\hline$T$ & Air te & mperature (K) \\
\hline$T_{\text {ch_mix }}$ & The sc & roll expander chamber temperature when the mixture filled in $(\mathrm{K})$ \\
\hline $\mathbf{T}_{\text {park }}$ & Park $\mathrm{t}$ & ransformation matrix \\
\hline & Voltag & ge in the different axes for the PMSG modelling (Volt) \\
\hline
\end{tabular}




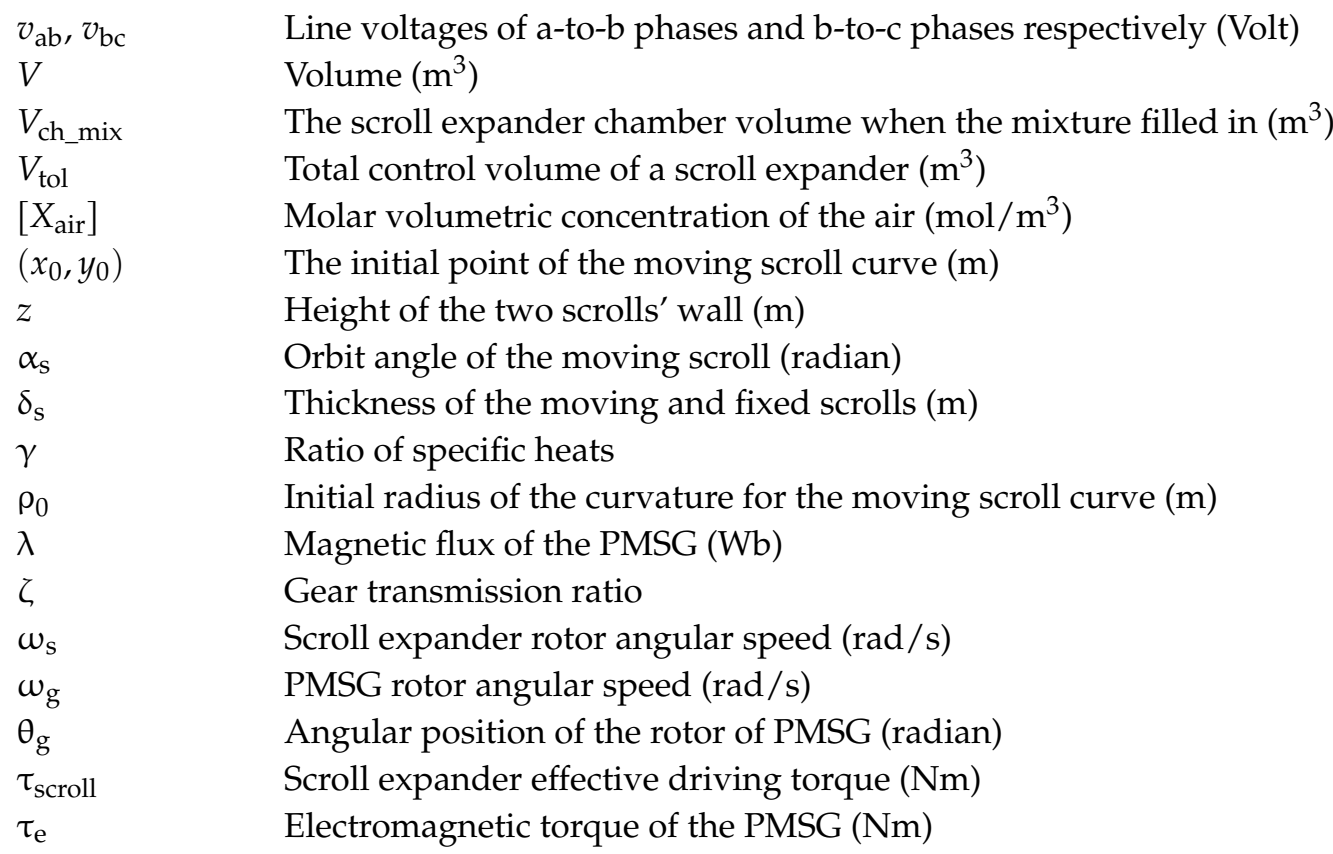

\section{Subscripts}

$\begin{array}{ll}a, b, c & \text { The } a, b, c \text { axes for the PMSG modelling } \\ \text { chamber } & \text { The scroll expander chamber } \\ d, q & \text { The } d, q \text { axes for the PMSG modelling } \\ i & \text { Species } i \text { containing in the post-combustion mixture from the engine } \\ \text { in,out } & \text { combustion process } \\ s c, s s, s e & \text { The inlet and outlet of scroll expander }\end{array}$

Abbreviations

\begin{tabular}{|c|c|}
\hline $\mathrm{AC}$ & Alternating current \\
\hline CAB & Compressed air battery \\
\hline $\mathrm{C}_{8} \mathrm{H}_{18}$ & Octane \\
\hline $\mathrm{CO}_{2}$ & Carbon dioxide \\
\hline DC & Direct current \\
\hline EGR & Exhaust gas recirculation \\
\hline HCCI & Homogeneous charge compression ignition \\
\hline $\mathrm{HP}$ & High pressure \\
\hline $\mathrm{H}_{2} \mathrm{O}$ & Water \\
\hline LP & Low pressure \\
\hline Micro CHP & Micro combined hear \& power system \\
\hline $\mathrm{NO}_{X}$ & Nitrogen oxides \\
\hline $\mathrm{O}_{2}$ & Oxygen \\
\hline PMSG & Permanent magnet synchronous generator \\
\hline SI & Spark-ignition \\
\hline UPS & Uninterrupted power supply \\
\hline
\end{tabular}




\section{References}

1. UK Department for Transport. Vehicle Licensing Statistics: Quarter 4 (October-December). Available online: https://www.gov.uk/government/statistics/vehicle-licensing-statistics-2014 (accessed on 16 October 2015).

2. Chinese Ministry of Public Security. The Rapid Increase of Motor Vehicles and Drivers in 2014. Available online: http:/ /www.mps.gov.cn/n16/n1252/n1837/n2557/4330449.html (accessed on 16 October 2015).

3. Hedges \& Company. United States Vehicle Ownership Data, Automobile Statistics and Trends. Available online: http://hedgescompany.com/automotive-market-research-statistics/auto-mailing-lists-and-marketing (accessed on 18 October 2015).

4. US Department of Energy. Where the Energy Goes: Gasoline Vehicles, The Official U.S. Government Source for Fuel Economy 25 Information. Available online: https:/ /www.fueleconomy.gov/feg/atv.shtml (accessed on 20 October 2015).

5. Baglione, M.; Duty, M.; Pannone, G. Vehicle system energy analysis methodology and tool for determining vehicle subsystem energy supply and demand. In Proceedings of the 2007 SAE World Congress, Detroit, MI, USA, 16-19 April 2007.

6. EU $\mathrm{CO}_{2}$ Emission Standards for Passenger Cars and Light-Commercial Vehicles. Available online: http://www.theicct.org/sites/default/files/publications/ICCTupdate_EU-95gram_jan2014.pdf (accessed on 20 October 2015).

7. Jia, N.; Wang, J.; Nuttall, K.; Wei, J.; Xu, H.; Wyszynski, M.L.; Qiao, J.; Richardson, M.J. HCCI engine modeling for real-time implementation and control development. IEEE/ASME Trans. Mechatron. 2007, 12, 581-589. [CrossRef]

8. Khodabakhshian, M.; Feng, L.; Wikander, J. Predictive control of the engine cooling system for fuel efficiency improvement. In Proceedings of the IEEE International Conference on Automation Science and Engineering (CASE), Taipei, Taiwan, 18-22 August 2014; pp. 61-66.

9. Romagnoli, A.; Wan-Salim, W.S.-I.; Gurunathan, B.A.; Martinez-Botas, R.F. Assessment of supercharging boosting component for heavily downsized gasoline engines. In Proceedings of the 11th International Conference on Turbochargers and Turbocharging, London, UK, 13-14 May 2014.

10. Lampton, C. How Exhaust Heat Recovery and Recirculation Works. How Stuffworks Website. Available online: http://auto.howstuffworks.com/fuel-efficiency/hybrid-technology/exhaust-heat-recoveryrecirculation.htm (accessed on 20 October 2015).

11. Bari, S.; Hossain, S.N. Design and optimization of compact heat exchangers to be retrofitted into a vehicle for heat recovery from a diesel engine. Procedia Eng. 2015, 105, 472-479. [CrossRef]

12. Hossain, S.N.; Bari, S. Waste heat recovery from exhaust of a diesel generator set using organic fluids. Procedia Eng. 2014, 90, 425-430. [CrossRef]

13. Bari, S.; Rubaiyat, S. Additional power generation from the exhaust gas of a diesel engine using ammonia as the working fluid. In Proceedings of the SAE 2014 World Congress \& Exhibition, Detroit, MI, USA, 8-10 April 2014.

14. Vance, J.B.; Singh, A.; Kaul, B.C.; Jagannathan, S.; Drallmeier, J.A. Neural network controller development and implementation for spark ignition engines with high EGR levels. IEEE Trans. Neural Netw. 2007, 18, 1083-1100. [CrossRef] [PubMed]

15. Park, Y.; Bae, C. Experimental study on the effects of high/low pressure EGR proportion in a passenger car diesel engine. Appl. Energy 2014, 133, 308-316. [CrossRef]

16. Ibrahim, A.; Bari, S. Effect of varying compression ratio on a natural gas SI engine performance in the presence of EGR. Energy Fuels 2009, 23, 4949-4956. [CrossRef]

17. Ibrahim, A.; Bari, S.; Bruno, F. A study on EGR utilization in natural gas SI engines using a two-zone combustion model. SAE Tech. Paper 2007. [CrossRef]

18. Yanagisawa, T.; Fukuta, Y.; Ogi, T.; Hikichi, T. Performance of an oil-free scroll-type air expander. In Proceedings of the ImechE Conference Trans on Compressors and Their Systems, Hamamatsu, Japan, 9-12 September 2001; pp. 167-174.

19. Luo, X.; Sun, H.; Wang, J. An energy efficient pneumatic-electrical system and control strategy development. In Proceedings of the American Control Conference, San Francisco, CA, USA, 29 June-1 July 2011; pp. 4743-4748. 
20. Wang, J.; Luo, X.; Yang, L.; Shpanin, L.M.; Jia, N.; Mangan, S.; Derby, J.W. Mathematical Modeling Study of Scroll Air Motors and Energy Efficiency Analysis-Part II. IEEE/ASME Trans. Mechatron. 2011, 16, 122-132. [CrossRef]

21. Flow Battery Ltd. Website. Case Study of Compressed Air Batteries (CAB) Application. Available online: http://www.flowbattery.co.uk/case-studies/national-grid-case-study (accessed on 21 October 2015).

22. Gao, X.; Li, L.S.; Zhao, Y.; Shu, P.C.; Shen, J. Research on a scroll expander used for recovering work in a fuel cell. Int. J. Thermodyn. 2004, 7, 1-8.

23. Luo, X.; Wang, J.; Sun, H.; Derby, J.W.; Mangan, S.J. Study of a New Strategy for Pneumatic Actuator System Energy Efficiency Improvement via the Scroll Expander Technology. IEEE/ASME Trans. Mechatron. 2013, 18, 1508-1518. [CrossRef]

24. Dieckmann, J. Waste heat waste heat-to-power using scroll expander for Organic Rankine Bottoming Cycle. U.S. DOE Advanced Manufacturing Office Peer Review Meeting Presentation. Available online: http:/ /energy.gov/sites/prod/files/2014/06/f16/14-TIAX_AMO_RD_Project_Peer_Review_2014.pdf (accessed on 21 October 2015).

25. Wang, J.; Yang, L.; Luo, X.; Mangan, S.; Derby, J.W. Mathematical Modeling Study of Scroll Air Motors and Energy Efficiency Analysis-Part I. IEEE/ASME Trans. Mechatron. 2011, 16, 112-121. [CrossRef]

26. Sun, H.; Luo, X.; Wang, J. Feasibility study of a hybrid wind turbine system-Integration with compressed air energy storage. Appl. Energy 2015, 137, 617-628. [CrossRef]

27. Luo, X.; Sun, H.; Wang, J. A Novel Magnetic Scroll Expander as a Drive for Electricity Generation. In Proceedings of the 7th IET International Conference on Power Electronics, Machines and Drives, Manchester, UK, 8-10 April 2014; pp. 1-6.

28. Fitzgerald, A.E.; Kingsley, C.; Stephen, D.U. Electric Machinery, 5th ed.; McGraw-Hill Inc.: Singapore, 1992; pp. 254-272.

29. Grenier, D.; Dessaint, L.A.; Akhrif, O.; Bonnassieux, Y.; Le Pioufle, B. Experimental nonlinear torque control of a permanent-magnet synchronous motor using saliency. IEEE Trans. Ind. Electron. 1997, 44, 680-687. [CrossRef]

30. Heywood, J. Internal Combustion Engine Fundamentals; McGraw-Hill, Inc.: New York, NY, USA, 1988; pp. 371-470.

31. Ceviz, M.A.; Kaymaz, İ. Temperature and air-fuel ratio dependent specific heat ratio functions for lean burned and unburned mixture. Energy Convers. Manag. 2005, 46, 2387-2404. [CrossRef]

32. Quoilin, S.; Declaye, S.; Legros, A.; Guillaume, L.; Lemort, V. Working fluid selection and operating maps for Organic Rankine Cycle expansion machines. In Proceedings of the 21st International Compressor Conference, West Lafayette, IN, USA, 14-19 July 2012; Volume 1546, pp. 1-10.

33. Wei, J.L.; Wang, J.; Wu, Q.H. Development of a Multisegment Coal Mill Model Using an Evolutionary Computation Technique. IEEE Trans. Energy Convers. 2007, 22, 718-727. [CrossRef] 